\title{
Heavy Metals in Soils and Road Dusts in Akure City, Southwest Nigeria: Ecological and Health Risks
}

Adeniyi JohnPaul Adewumi ( $\square$ adewumiadeniyi27@yahoo.com )

Achievers University https://orcid.org/0000-0003-1091-743X

\section{Research Article}

Keywords: Akure, Ecological Risks, Health Risks, Heavy Metals, Road Dusts, Soils

Posted Date: September 14th, 2021

DOI: https://doi.org/10.21203/rs.3.rs-860764/v1

License: (c) (i) This work is licensed under a Creative Commons Attribution 4.0 International License. Read Full License 


\section{Heavy Metals in Soils and Road Dusts in Akure City, Southwest Nigeria: Ecological and Health Risks}

\section{Adewumi, A.J.}

Department of Geological Sciences, Achievers University, Owo, Ondo State, Nigeria

*E-mail address: adewumiadeniyi27@ yahoo.com; adewumiadeniyi@ achievers.edu.ng

ORCID Number: 0000-0003-1091-743X

\section{Abstract}

Expanded urbanization particularly in developing nations have as of late become a significant source of worry because of their adverse consequences on the environment. This study was conducted to determine the extent of pollution, sources, and potential ecological and health risks associated with heavy metals in Akure region, Nigeria's soils and street dusts. Thirty-four samples including 16 soils and street dusts samples each were gathered with two control samples gathered from a suburb a long way from the city. To collect fine particles, they were air dried and sieved. Chemical analysis of samples werecarried out utilizing Atomic Absorption Spectrometer (AAS) at Sustainable laboratory, a certified laboratory in Akure, Nigeria. Metals analysed were: $\mathrm{As}, \mathrm{Cd}, \mathrm{Co}, \mathrm{Cr}, \mathrm{Cu}, \mathrm{Ni}, \mathrm{Pb}, \mathrm{Zn}$ and $\mathrm{Fe}$. Contamination, ecological and health hazard evaluations were carried out utilizing universally acceptable indices. Potential sources were disentangle utilizing measurable technique like bivariate, factor and hierarchical cluster analyses. Results uncovered that the mean amount of $\mathrm{Pb}, \mathrm{Zn}$ and Fe in street dusts were: $32.33 \mathrm{mg} / \mathrm{kg}, 72.53 \mathrm{mg} / \mathrm{kg}$, and $115.21 \mathrm{mg} / \mathrm{kg}$ separately while in soil tests it was $34.34 \mathrm{mg} / \mathrm{kg}, 67.76 \mathrm{mg} / \mathrm{kg}$, and $115.21 \mathrm{mg} / \mathrm{kg}$. The examination further showed that metals particularly $\mathrm{Cr}$ present slight to high ecological dangers. Health hazard evaluation uncovered that the occupants of the area particularly kids are more inclined to non-cancer-causing health risks. Metals were mostly from anthropogenic sources. To reduce 
the impact of toxic metals in the city, it is proposed that ecological enactment and mindfulness be practiced..

Keywords: Akure; Ecological Risks; Health Risks; Heavy Metals; Road Dusts; Soils

\section{Introduction}

Soil is a fundamental natural resource on account of its capacity to go about as a geochemical sink for various foreign substances, including possibly poisonous metals coming about because of aerial deposition through metropolitan and other human exercises (Pouyat et al. 2020). Quick, constant and disorderly industrialization and urbanization have prompted ecological weakening and defilement (Seto et al. 2012; Yao et al. 2021). Climatic contamination is one of the major natural issues that contributes monstrously to metropolitan ecological issues (Seto et al. 2012; Lu et al. 2017). Human exercises like mining (Oyebamiji et al. 2018; Adewumi et al. 2020), refining (Strezov and Chaudhary, 2017), petroleum derivative ignition (Lelieveld et al. 2019) and garbage removal (Laniyan and Adewumi, 2019) have prompted evidences of conceivably poisonous metals in soils of Metropolitan focuses which brings about extreme ecological debasement. A few examinations across the world explored the effect of poisonous metals on metropolitan soils in Saudi Arabia (AlBoghdady et al. 2019), Nigeria (Adedeji et al. 2018), Iran (Aminiyan et al. 2016, Ghanavati et al. 2019), Algeria (Benhaddya et al. 2015) and dusts in China (Yang et al. 2015), Thailand (Mama and Singhirunnusorn, 2012), Algeria (Benhaddya et al. 2015), Iran (Ghanavati et al. 2019).

Occupants ofcities are a lot and are inconsistent disseminated and devours extreme measure of normal assets accordingly delivering huge measure of foreign substances into the climate (Li, 2018). Individuals living in Metropolitan regions are presented to wellbeing 
hazards related with heavy metals in soils (Adedeji et al. 2018), water (Laniyan and Adewumi, 2019) and vaporizers (Ghanavati et al. 2019) through inward breath, ingestion and dermal contact retention (Madrid et al., 2002; DeMiguelet al., 2007). Youngsters are more inclined to the effect of soil contamination, especially in urban areas, because of regular hand-mouth action and higher retention rate in contrast with grown-ups (Zheng et al., 2010; Basta and Juhasz, 2014). This is incredible in light of the fact that it tends to hazardous and causes wellbeing (Kelepertzis, 2014).

It has been projected that by 2050 , the number of inhabitants in Nigeria will significantly increase in contrasts to its present populace of more than 200 million individuals (Statista, 2021). Nigeria is presently the biggest economy in Africa (WPR, 2021) which is has led to increase in human related activities. Expanded urbanization, industrialization and serious anthropogenic activities in country like Nigeria, will lead to incremental harmful metal pollution. Subsequently there is a need to ceaselessly screen the degree of metal focus in the city. Environmental studies in Akure include assessment of anthropogenic influence of toxic metals on soils (Oguntimehin and Ipinmoriti, 2008; Olorundare et al. 2011, Anietie and Labunmi, 2015, Olutola 2018, Aiyesanmi et al., 2020), water (Olutola 2018) and plants (Olutola 2018, Aiyesanmi et al., 2020). None of these studies looked at the amount of harmful metal pollution in the city's roadway dust. Furthermore, none of these studies looked into the environmental and health problems associated with heavy metals in municipal soils and street dusts. As a result, the objectives of this research are to: (1) determine the concentrations and extent of contamination of selected potentially toxic metals (PTM) in soils and road dusts in Akure Metropolis, Southwest Nigeria; (2) assess the degree of ecological and health risks associated with metals in the media; and (3) identify potential sources of metals in media collected from the area. 


\section{Materials and Methods Study Area}

Akure is situated in Southwest Nigeria and is the biggest city and capital of Ondo State and fills in as a business center point for different towns around the state. It lies between latitude $7^{\circ} 15^{\prime} 9.22^{\prime \prime} \mathrm{N}$ and longitude $5^{\circ} 11^{\prime} 35.23^{\prime \prime} \mathrm{E}$ (Fig. 1). It is around $311 \mathrm{~km}$ north of Lagos city. The region has a tropical climate and is extraordinarily impacted by downpour bearing southwest rainstorm twists from the sea and the dry northwest breezes from Sahara Desert. The city encounters huge precipitation in many months with a the normal precipitation of $2378 \mathrm{~mm}$ and a short dry season with $405 \mathrm{~mm}$ and $19 \mathrm{~mm}$ of precipitation in September and December separately. The normal yearly temperature is $26.7^{\circ} \mathrm{C}$ (climatedata.org, 2019). The regular vegetation is the high backwoods, made out of numerous assortments of hardwood wood, for example, Meliciaexcelsa and Terminalia superba.The study region has a rise of 399 meters above ocean level. The noticeable waterway in the investigation region is Ala River and it patterns in the NW-SE course. The seepage framework over the space is of the multiplication of numerous little stream channels. The more modest streams are occasional particularly from month November to May. Geologically, the area is located within the Basement Complex of Nigeria which have undergone series of tectonic deformation (Adewumi et al, 2018).

\section{Sample Collection}

An aggregate of 34 samples were gathered which incorporate 16 soil samples which were collected around 5 meters from the major motorable streets and 16 street dusts samples by the side of the significant roads. Control samples for soils and road dusts were taken at Ibule-soro town around $5 \mathrm{~km}$ from Akure city. Soil tests were gathered utilizing an random sampling method. Samples were put in a spotless all around named ziplock pack utilizing pre-washed hand-drill. Up to $20 \mathrm{~kg}$ of each example were gathered at $10 \mathrm{~cm}$ underneath the 
surface. Prior to testing at each point, the hand drill and hand scoop were totally washed with refined water and was permitted to dry to keep away from tainting of samples from obscure sources. At each examining point, accurate GPS readings were taken utilizing Etrex Garmin Global Positioning System (GPS). Street dusts were gathered along significant roads and created street side asphalts in the city. They were gathered with a brush on a spotless parker. Up to $5 \mathrm{~kg}$ composite of each example were gathered on each road side. Samples were set in a perfect all around named ziplock sack. Prior to inspecting, the hand scoop was entirely washed with refined water and permitted to dry before the following sample is taken.

\section{Sample Preparation and Chemical Digestion}

All soils and street dusts samples gathered during fieldwork were isolated from each other and were appropriately marked to keep away from their stir up. After this, all samples were dried at room temperature until all out dryness was accomplished. In the wake of drying, 200g of the example was gauged utilizing electronic gauging balance and were precisely sieved utilizing a sedimentological sieve and shaker for 15 minutes at $70 \mathrm{rpm}$. The shaker isolates the examples into various grain sizes from coarse to exceptionally fine. Grains under $10 \mathrm{~mm}$ were gathered and put away in a little ziplock packs which were marked appropriately to keep away from samples stir up. A while later $1 \mathrm{~g}$ of samples were gauged utilizing electronic gauging balance and set into Teflon tubes utilizing aqua regia in proportion 1:3 of $\mathrm{HNO}_{3}$ and $\mathrm{HCl}$. This was then positioned in a metallic holder. The holders were placed in a broiler for 16 hours at 110 degrees Celsius before being transported to a hotplate. On the hotplate, the digestate was allowed to warm up until it was almost dry, then $5 \mathrm{ml}$ of acids were added. The digestates were attenuated with ultrapure water at a ratio of 1:50 after a thorough processing of the samples. At a certified laboratory, Sustainable laboratory, Akure, Atomic Absorption Spectroscopy (AAS) was used to study each metal. $\mathrm{As}, \mathrm{Cu}, \mathrm{Cd}, \mathrm{Co}, \mathrm{Cr}, \mathrm{Ni}, \mathrm{Pb}, \mathrm{Zn}$, and $\mathrm{Fe}$ were found in soils and street dusts. Time period tests 
were used to estimate normalized samples from the research facility as quality control for the evaluation.

\section{Statistical analysis and plotting of spatial map}

Information acquired from chemical examination of samples were exposed to statistical investigation utilizing SPSS $^{\mathrm{TM}} 23.0$ version. Measurable investigation did incorporate descriptive, principal component/factor analysis, hierarchical cluster and bivariate analysis. All spatial maps created for this examination were plotted utilizing Surfer $10^{\mathrm{TM}}$.

\section{Contamination Assessment}

The geo-accumulation index (Igeo), Enrichment Factor (EF), Contamination Factor (CF), Pollution Load Index (PLI), and Contamination Degree (CD) were used to measure samples contamination.

\section{Geo-accumulation index (Igeo)}

The geo-accumulation index (Igeo) was developed to evaluate metal enrichment above baseline values in order to determine contamination of a specific metal in soils. Equation 1 was used to calculate Igeo (Muller, 1969). Igeo $<0$ (unpolluted); $0 \leq$ Igeo $<1$ (unpolluted to moderately polluted); $1 \leq$ Igeo $<2$ (moderately polluted); $2 \leq$ Igeo $<3$ (Moderately to heavily polluted); $3 \leq$ Igeo $<4$ (Heavily polluted); $4 \leq$ Igeo $<5$ (Heavily to extremely polluted) and Igeo $\geq 5$ (Extremely polluted).

$$
\text { Igeo }=\log _{2}\left(\frac{C n}{1.5 * B n}\right)
$$

The constant 1.5 is introduced to reduce the effect of any variations in the background values that may be attributable to lithologic variations in the sediments, where $\mathrm{Cn}$ is the metal concentration in the sample and $\mathrm{Bn}$ is the metal concentration in the background sample. 
Contamination factor $(\mathrm{CF})$ in outline Equation 2 was used to determine the level of heavy metal contamination in soil. CF is a single-element index with four distinct classes (Hakanson, 1980). These are: $\mathrm{CF} \leq 1$ (Low contamination factor); $1 \leq \mathrm{CF}<3$ (Moderate contamination factor); $3 \leq \mathrm{CF}<6$ (Considerable contamination factor), and $6 \geq \mathrm{CF}$ (Very high contamination factor).

Contamination Factor $=$

Metal Concentration in soils

/ Concentration of elements in background soils

Enrichment Factor (EF)

The element's enrichment factor (EF) is used to determine the amount of metal present in a media. It is based on the comparison of a measured element to a reference element for standardization. In this investigation, Fe was utilized as a normalizer. (Li et al., 2001; Sezginet al., 2003; Duzgoren-Aydin, 2007). The EF calculation is expressed in Equation 3.

$$
E F=\frac{\left(\frac{\text { Metal }}{R E}\right) \text { Soil }}{\left(\frac{\text { Metal }}{R E}\right) \text { Background }}(\text { Equation 3) }
$$

Where RE is the Reference Metal Concentration. On the basis of the enrichment factor, five contamination categories are recognized: $\mathrm{EF}<2$ states deficiency to minimal enrichment, $\mathrm{EF}$ $=2-5$ moderate enrichment, $\mathrm{EF}=5-20$ significant enrichment, $\mathrm{EF}=20-40$ very high enrichment and EF > 40 extremely high enrichments (Duzgoren-Aydin et al., 2006).

Pollution Load Index (PLI) used to assess the extent of metal pollution at each sampling station..

$$
P L I=\sqrt[n]{C F_{1} \times C F_{2} \times \ldots \times C F_{n}}
$$


where $\mathrm{n}$ is the number of metals investigated, and CF denotes the contamination factor as given in Equation 4. It gives a simple yet comparative technique of assessing a site's quality, with a PLI value of 1 indicating perfection, PLI= 1 indicating just baseline levels of pollutants, and PLI > 1 indicating worsening of site quality (Tomilson et al., 1980).

\section{Contamination Degree (CD)}

The sum of contamination factors for all elements investigated is the contamination degree, which offers a measure of overall contamination in surface layers at a given test site (Hakanson, 1980). The CD is divided into four categories. Equation 5 shows the formula for determining $\mathrm{CD}$. of the $\mathrm{CD}$ are: $\mathrm{CD}<8$ (low degree of pollution); $8 \leq \mathrm{CD}<16$ (Moderate level of pollution); $16 \leq \mathrm{CD}<32$ (Considerable degree of pollution); $\mathrm{CD} \geq 32$ (Very high degree of pollution).

$$
\mathrm{Cd}=\sum_{i=1}^{n} \mathrm{CF}
$$

The Contamination Degree is Cd, while the Contamination Factor is CF.

\section{Assessment of Ecological Risk of Heavy Metals}

The ecological risk index is used to assess heavy metal contamination for its ecological and environmental effects as well as toxicity. $\mathrm{As}, \mathrm{Cu}, \mathrm{Co}, \mathrm{Cd}, \mathrm{Ni}, \mathrm{Pb}$, and $\mathrm{Zn}$ have toxic response factor (Tri) 20, 5, 1, 30, 2, 5, 5, and 1 ( $\mu / \mathrm{g}$ ), respectively (Hakanson 1980). Equation 6 is used to calculate ER.

$$
E_{R}^{i}=T_{R}^{i} \times c_{R}^{i}
$$

The toxic-response factor is $\mathrm{Tr}$, while the single-element pollution factor is $\mathrm{CF}$. The following are the ERI's classifications: ER $<40$ (slight ecological risk); 40> ER $<80$ (medium ecological risk); 80> ER <160 (high ecological risk); 160> ER <320 (higher ecological risk) and ER >320 (highest ecological risk).

\section{Potential Ecological Risk Index (PERI)}


PERI is used to calculate a semi-quantitative assessment of regional pollution levels.

Equation 7 (Wang et al., 2015) can be used to express it:

$$
\text { PERI }=\sum_{\mathrm{i}=1}^{\mathrm{m}} \mathrm{E}_{\mathrm{R}}^{\mathrm{i}}
$$

197

where ER denotes a single element's potential ecological risk. The following are the RI classifications: $\mathrm{RI}<50$ (Slight risk index); 150 $>\mathrm{RI}<300$ (Medium risk index); 300 $>\mathrm{RI}<600$ (High to higher risk index) and $\mathrm{RI} \geq 600$ (Highest risk index).

\section{Health Risk Assessment of Heavy Metals}

Heavy metal exposure pathways in polluted soils are computed using recommendations from multiple American publications. The following exposure equations (equations 8 to 14 ) were used to compute ADI ( $\mathrm{mg} / \mathrm{kg} / \mathrm{day}$ ) for the various routes as provided by (USEPA, 1989).

\section{Heavy Metal Consumption}

Equation 8 shows the average daily intake of heavy metals through soil/dust ingestion.

$$
A D I_{\text {ing }}=\frac{C \times I R \times E F \times E D \times C F}{B W \times A T}
$$

$\mathrm{C}$ is the concentration of heavy metal in $\mathrm{mg} / \mathrm{kg}$ for soil/dust, and ADling is the average daily intake of heavy metals eaten from soil in $\mathrm{mg} / \mathrm{kg}$-day. The intake rate is measured in milligrams per day. The exposure frequency is measured in days per year. The exposure duration (ED) is measured in years. BW is the exposed person's body weight in kilograms.

The time period over which the dose is averaged in days is referred to as AT. The conversion factor in $\mathrm{kg} / \mathrm{mg}$ is $\mathrm{CF}$ (Supplementary 1).

\section{Inhalation of Heavy Metals}

Equation 9 shows the average daily intake of heavy metals by soil breathing.

$$
A D I_{\text {inh }}=\frac{C_{s} \times I R_{\text {air }} \times E F \times E D}{B W \times A T \times P E F}
$$


In $\mathrm{mg} / \mathrm{kg} / \mathrm{day}$, ADIinh is the average daily intake of heavy metals inhaled via soil/dust. The quantity of heavy metals in soil/dust is measured in milligrams per kilogram $(\mathrm{mg} / \mathrm{kg})$. The inhalation rate in m3/day is IRair. The particle emission factor (PEF) is measured in milligrams per kilogram. EF, ED, BW, and AT are defined in Equation 9 previously (Supplementary 1).

\section{Dermal Contact with Heavy Metals}

Equation 10 depicts the average daily intake of heavy metals by cutaneous contact with soil.

$$
A D I_{i n h}=\frac{C_{s} \times S A \times A F \times A B S \times E F \times E D \times C F}{B W \times A T}
$$

Where ADIdems is the exposure dosage in $\mathrm{mg} / \mathrm{kg} / \mathrm{day}$ by dermal contact. The heavy metal concentration in soil is measured in milligrams per kilogram $(\mathrm{mg} / \mathrm{kg})$. The exposed skin area (SA) is measured in square centimeters $\left(\mathrm{cm}^{2}\right)$. The percentage of the dermal exposure ratio in soil is called FE. The soil adherence factor (AF) is measured in milligrams per square meter. The proportion of the dermal dosage absorbed over the skin is referred to as ABS. Equation 9 defines the terms EF, ED, BW, CF, and AT. The exposure parameters utilized for the health risk assessment for a standard home exposure scenario along several exposure paths are shown in supplementary 1.

\section{Assessment of Non-Carcinogenic Health Risks}

The hazard quotient is a concept used to describe non-carcinogenic dangers (HQ). The likelihood of an individual receiving an undesirable outcome is expressed as a unit less number. As indicated in Equation (11) it is defined as the quotient of ADI divided by the toxicity threshold value, which is known as the chronic reference dose (RfD) in $\mathrm{mg} / \mathrm{kg} / \mathrm{day}$ of a certain metal (USEPA, 1989).

$$
H Q=\frac{A D I}{R f D}
$$


237 The Hazard index (HI) is a word used by the USEPA to describe the sum of all HQs (1989).

238 The mathematical expression of $\mathrm{HI}$ is Equation 12.

$$
H I=\sum_{k=1}^{n} H Q k=\sum_{k=1}^{n} \frac{A D I k}{R f D k}
$$

239 The values of heavy metal $\mathrm{k}$ are HQk, ADIk, and RfDk (Supplementary 2). The exposed 240 population is unlikely to suffer negative health impacts if the HI value is less than one. If the 241 HI value is more than one, there may be cause for concern about non-carcinogenic effects 242 (USEPA, 1989).

\section{Assessment of Carcinogenic Health Risk}

244 The hazards of carcinogens are calculated as the incremental probability of a person 245 developing cancer over their lifetime as a result of exposure to the suspected carcinogen. The 246 increased lifetime cancer risk is calculated using Equation 13.

$$
\operatorname{Risk}_{\text {pathway }}=\sum_{k=1}^{n} A D I_{k} C S F_{k}
$$

247 Where Risk is the chance of an individual developing cancer during their lifetime, and $\operatorname{ADIk}(\mathrm{mg} / \mathrm{kg} / \mathrm{day})$ and $\operatorname{CSFk}(\mathrm{mg} / \mathrm{kg} / \mathrm{day})$ are the average daily intake and cancer slope factor, respectively, for the kth and nth heavy metals (Supplementary 2). The slope factor turns an individual's lifetime exposure to a metal's anticipated daily intake into an incremental chance of acquiring cancer (USEPA, 1989). Equation 14 is used to calculate the overall increased lifetime cancer risk.

$$
\text { Risk }_{\text {total }}=\text { Risk }_{\text {ing }}+\text { Risk }_{\text {ink }}+\text { Ris }_{\text {dermal }}
$$

253 Where Risk(ing), Risk(inh), and Risk(dermal) denote risk contributions by ingesting, inhalation, and dermal routes, respectively.

\section{Results}



samples taken from the research area. The average percentage distribution of sand in soils is 98.50, with AS9 having the lowest value (96.74\%) and AS10 having the greatest value (99.75\%). The average percentage distribution of silt is $0.66 \%$ with AS10 having the lowest value of $0.02 \%$ and AS4 having the highest value of $1.65 \%$. The mean amount of clay in the soil samples is $0.84 \%$ with sample AS8 having the lowest vlaue of $0.02 \%$ and AS9 having the highest value of $2.67 \%$. For road dust samples, the average percentage distribution of sand is $96.15 \%$, with RD3 having the lowest value of $88.93 \%$ and RD15 having the highest value of $99.05 \%$. The average percentage distribution of silt is $1.84 \%$ with RD12 having the lowest value of $0.02 \%$ and RD8 having the highest value of $6.39 \%$. The mean amount of clay in the dust samples is $2.00 \%$ with sample RD6 having the lowest vlaue of $0.38 \%$ and RD3 having the highest value of $5.03 \%$.

\section{Human Activities and Vehicular Intensity}

Figure 2 depicts the percentage of human activities and vehicular activity in the research region around soil and road dust sampling stations. Forty (40) percent of the study area comprises of residential areas while $3 \%, 7 \%, 2 \%, 4 \%, 22 \%, 9 \%, 2 \%$ and $11 \%$ are made up of cocoa processing industry, dumpsite, quarry, cement depots, mechanic shops, schools, motor parks and markets respectively. The study uncovered that in the area $12 \%, 49 \%, 27 \%$ and $12 \%$ represents low, intense, high and normal vehicular intensities respectively.

\section{Metals with Toxic Potential in Soils and Road Dust}

Table 1 shows the concentrations of potentially harmful metals in road dust and soils in Akure metropolis. The average concentrations of $\mathrm{As}, \mathrm{Cu}, \mathrm{Cd}, \mathrm{Co}, \mathrm{Cr}, \mathrm{Ni}, \mathrm{Pb}, \mathrm{Zn}$, and $\mathrm{Fe}$ in metropolis road dusts were $1.80 \mathrm{mg} / \mathrm{kg}, 37.69 \mathrm{mg} / \mathrm{kg}, 3.02 \mathrm{mg} / \mathrm{kg}, 38.68 \mathrm{mg} / \mathrm{kg}, 3.17 \mathrm{mg} / \mathrm{kg}$, 
value for all hazardous elements in road dusts is less than 0.01 . These results were higher

282

283

284

285

286

287

288

289

290

291

292

293

294

295

296

297

298

299

300

301

302

303

304

than the background dust samples' concnetration. Furthermore, the samples contained levels of As, Cd, and $\mathrm{Zn}$ that exceeded the USEPA's permitted limits (2002). The average amounts of As, $\mathrm{Cu}, \mathrm{Cd}, \mathrm{Co}, \mathrm{Cr}, \mathrm{Ni}, \mathrm{Pb}, \mathrm{Zn}$, and Fe in the city's soils were $1.67 \mathrm{mg} / \mathrm{kg}, 36.29 \mathrm{mg} / \mathrm{kg}$, $1.87 \mathrm{mg} / \mathrm{kg}, 27.40 \mathrm{mg} / \mathrm{kg}, 27.68 \mathrm{mg} / \mathrm{kg}, 10.07 \mathrm{mg} / \mathrm{kg}, 34.34 \mathrm{mg} / \mathrm{kg}, 67.76 \mathrm{mg} / \mathrm{kg}$, and 115.21 $\mathrm{mg} / \mathrm{kg}$, according to the study. All heavy metals in the city's soils have a significance value of less than 0.01 . These values were higher than the background soil samples' concnetration. Furthermore, the levels of $\mathrm{As}, \mathrm{Cd}, \mathrm{Cr}$, and $\mathrm{Zn}$ in the soil samples were higher than the USEPA's permitted limits (USEPA, 2002).

\section{Potentially Toxic Metals Contamination of Soils and Dusts}

Table 3 shows the geo-accumulation index (Igeo) of potentially harmful metals in soils and road dusts from the research area. For $\mathrm{As}, \mathrm{Cd}, \mathrm{Co}, \mathrm{Cr}, \mathrm{Cu}, \mathrm{Ni}, \mathrm{Pb}, \mathrm{Zn}$, and $\mathrm{Fe}$ in soils, the average Igeo is $0.71,1.55,-0.02,0.33,0.41,1.67,0.97,0.46$, and -0.66 respectively. For road dusts, Igeo is $2.27,2.78,0.98,2.62,0.64,1.14,0.68,1.82$, and 0.66 for $\mathrm{As}, \mathrm{Cd}, \mathrm{Co}, \mathrm{Cr}, \mathrm{Cu}$, $\mathrm{Ni}, \mathrm{Pb}, \mathrm{Zn}$, and $\mathrm{Fe}$, respectively.

Table 3 shows the enrichment factor (EF) of heavy metals in soils and road dusts from the research area. The mean $\mathrm{EF}$ for $\mathrm{As}, \mathrm{Cd}, \mathrm{Co}, \mathrm{Cr}, \mathrm{Cu}, \mathrm{Ni}, \mathrm{Pb}, \mathrm{Zn}$, and $\mathrm{Fe}$ is 2.89, 5.69, 1.80, $2.23,2.22,4.02,2.47,1.52$ and 1.00, respectively, while the mean EF for road dust samples is $3.48,5.08,0.96,4.39,1.12,1.19,1.21,1.66$ and 1.00 . In the research area, the mean contamination degree (CD) for soils and road dusts is 17.41 and 43.68 , respectively, and the pollution load index (PLI) for both samples is 2.09 and 3.79.

\section{Ecological Risks (ER) of Metals with Toxic Potential in Soils and Road Dust}

Table 4 shows the results of the ecological risks of heavy metals in soils and road dusts in the research region. In soils, the ER for As ranges from 20.60 to 85.00 , with a mean of 
55.60, whereas the ER for $\mathrm{Cu}$ ranges from 7.22 to 18.37 , with a mean of 10.79. The ER for $\mathrm{Zn}$ ranges from 0.89 to 1.79 , with a mean value of 1.38 . The ER for $\mathrm{Cd}$ ranges from 49.29 to 220.72 with an average of 160.91 , whereas the ER for Ni ranges from 4.86 to 35.00 with an average of 19.02. The ER for $\mathrm{Pb}$ ranges from 5.37 to 17.58 , with an average of 11.06. In Akure metropolitan, the risk index (RI) for soils ranges from 89.83 to 383.62 , with an average of 261.94 .

For road dusts, ER fo As is bewteen 84.00 and 216.80 with a mean of 151.20 while for $\mathrm{Cu}$ it is between 32.33 and 73.28 with an average of 54.72 . For $\mathrm{Zn}$ it is between 1.55 and 4.07 with a mean value of 2.51 . The ER for Cd ranges from 25.72 to 107.50 with an average of 63.72, whereas the ER for Ni ranges from 6.91 to 21.10 with a mean of 12.62 . The ER for $\mathrm{Pb}$ ranges from 4.60 to 21.79 , with an average of 12.17 . In Akure metropolitan, the risk index (RI) for soils ranges from 167.73 to 457.20 , with a mean value of 315.99 .

\section{Health Risks of Heavy Metals in Soils and Road Dusts}

Average Daily Intake of Heavy Metals for Children and Adults for Non-Carcinogenic Health Risks

The average daily intake (ADI) for heavy metals in soils and road dusts in children and adults for non-carcinogenic diseases are shown in Figure 5. Figure 5 showed that the total daily heavy metal intake from soil via ingestion, dermal contact and inhalation for noncarcinogenic diseases in children are: As: $2.17 \mathrm{E}-4 \mathrm{mg} / \mathrm{kg}$; $\mathrm{Cu}: 4.01 \mathrm{E}-3 \mathrm{mg} / \mathrm{kg}$; $\mathrm{Cd}: 2.5 \mathrm{E}-4$ $\mathrm{mg} / \mathrm{kg}$; Co: 3.57E-4 mg/kg; Cr: 2.53E-4 mg/kg; Ni: 1.31E-3 mg/kg; Pb: 4.48E-3 mg/kg; Zn: $8.8 \mathrm{E}-4 \mathrm{mg} / \mathrm{kg} ; \mathrm{Fe}: 1.56 \mathrm{E}-4 \mathrm{mg} / \mathrm{kg}$.

\section{Heavy Metals in Soils and Road Dusts: Health Risks}

Average Daily Heavy Metal Intake for Non-Carcinogenic Health Risks in Children and Adults 
Figure 5 depicts the average daily intake (ADI) of heavy metals in soils and road dusts in children and adults with non-carcinogenic disorders. Figure 5 shows that for noncarcinogenic disorders in children, the total daily heavy metal intake from soil via ingestion, skin contact, and inhalation is: $2.17 \mathrm{E}-4 \mathrm{mg} / \mathrm{kg}, \mathrm{Cu} 4.01 \mathrm{E}-3 \mathrm{mg} / \mathrm{kg}, \mathrm{Cd} 2.5 \mathrm{E}-4 \mathrm{mg} / \mathrm{kg}$, Co 3.57E-4 mg/kg, Cr 2.53E-4 mg/kg, Ni 1.31E-3 mg/kg, Pb 4.48E-3 mg/kg, Zn 8.8E-4 mg/kg, Fe $1.56 \mathrm{E}-4 \mathrm{mg} / \mathrm{kg}$ The total daily heavy metal intake from road dust via Table 4 demonstrated that for non-carcinogenic disorders in children, the total daily heavy metal intake from road dust via ingestion, cutaneous contact, and inhalation is: $\mathrm{Cu}: 4.92 \mathrm{E}-3 \mathrm{mg} / \mathrm{kg}$; Cd: $3.94 \mathrm{E}-4 \mathrm{mg} / \mathrm{kg}$; Co: $5.05 \mathrm{E}-3 \mathrm{mg} / \mathrm{kg}$; Cr: 4.14E-4 mg/kg; Ni: $1.62 \mathrm{E}-3 \mathrm{mg} / \mathrm{kg}$; Pb: $4.22 \mathrm{E}-3$ $\mathrm{mg} / \mathrm{kg}$; Zn: $9.47 \mathrm{E}-3 \mathrm{mg} / \mathrm{kg} ; \mathrm{Fe}: 1.51 \mathrm{E}-2 \mathrm{mg} / \mathrm{kg}$

For non-carcinogenic disorders, the total daily heavy metal intake from soil via ingestion, cutaneous contact, and inhalation for adults is: $\mathrm{Cu}: 4.30 \mathrm{E}-3 \mathrm{mg} / \mathrm{kg}$; $\mathrm{Cd}: 2.59 \mathrm{E}-5$ $\mathrm{mg} / \mathrm{kg}$; Co: 3.78E-5 mg/kg; Cr: 2.53E-4 mg/kg; Ni: 1.39E-4 mg/kg; Pb: 4.74E-4 mg/kg; Zn: $9.35 \mathrm{E}-4 \mathrm{mg} / \mathrm{kg}$; Fe: $1.65 \mathrm{E}-3 \mathrm{mg} / \mathrm{kg}$

\section{Average Daily Heavy Metal Intake for Carcinogenic Health Risks in Children and} Adults

Figure 5 shows the average daily intake (ADI) of heavy metals in soils and road dusts for carcinogenic illnesses in children and adults. Figure 5 shows the total daily heavy metal intake from soil for carcinogenic disorders in children by eating, cutaneous contact, and inhalation: As: $1.87 \mathrm{E}-5 \mathrm{mg} / \mathrm{kg}$; Cu: $3.50 \mathrm{E}-4 \mathrm{mg} / \mathrm{kg}$; Cd: $2.10 \mathrm{E}-5 \mathrm{mg} / \mathrm{kg}$; Co: $3.07 \mathrm{E}-4 \mathrm{mg} / \mathrm{kg}$; Cr: 2.17E-5 mg/kg; Ni: 1.13E-4 mg/kg; Pb: 3.84E-4 mg/kg; Zn: 7.59E-4 mg/kg; Fe: 1.34E-3 $\mathrm{mg} / \mathrm{kg}$; Ni: $1.13 \mathrm{E}-4 \mathrm{mg} / \mathrm{kg}$; Pb: 3.84E-4 mg/kg Figure 5 shows that for carcinogenic disorders in children, the total daily heavy metal intake from road dust via eating, cutaneous contact, and inhalation is: As: $1.87 \mathrm{E}-5 \mathrm{mg} / \mathrm{kg}$; Cu: $3.50 \mathrm{E}-4 \mathrm{mg} / \mathrm{kg}$; Cd: $2.10 \mathrm{E}-5 \mathrm{mg} / \mathrm{kg}$; Co: $3.07 \mathrm{E}-4$ 
$\mathrm{mg} / \mathrm{kg}$; Cr: 2.17E-5 mg/kg; Ni: 1.13E-4 mg/kg; Pb: 3.84E-4 mg/kg; Zn: 7.59E-4 mg/kg; Fe: 1.34E-3 mg/kg; Ni: $1.13 \mathrm{E}-4 \mathrm{mg} / \mathrm{kg} ; \mathrm{Pb}: 3.84 \mathrm{E}-4 \mathrm{mg} / \mathrm{kg}$ Figure 5 shows that for carcinogenic disorders in children, the total daily heavy metal intake from road dust via eating, cutaneous contact, and inhalation is: As: $2.01 \mathrm{E}-5 \mathrm{mg} / \mathrm{kg}$; Cu: $4.21 \mathrm{E}-4 \mathrm{mg} / \mathrm{kg}$; Cd: $3.38 \mathrm{E}-5 \mathrm{mg} / \mathrm{kg}$; Co: 4.32E-4 mg/kg; Cr: $3.55 \mathrm{E}-5 \mathrm{mg} / \mathrm{kg}$; Ni: $1.39 \mathrm{E}-4 \mathrm{mg} / \mathrm{kg} ; \mathrm{Pb}: 3.62 \mathrm{E}-4 \mathrm{mg} / \mathrm{kg}$; Zn: $8.11 \mathrm{E}-4$ $\mathrm{mg} / \mathrm{kg}$; Fe: $1.29 \mathrm{E}-3 \mathrm{mg} / \mathrm{kg}$; Zn: 8.11E-4 mg/kg; Fe: $1.29 \mathrm{E}-3 \mathrm{mg} / \mathrm{kg}$.

For non-carcinogenic disorders in children, the total daily heavy metal intake from soil via ingestion, cutaneous contact, and inhalation is: As is $9.87 \mathrm{E}-5 \mathrm{mg} / \mathrm{kg}$; $\mathrm{Cu}$ is $1.85 \mathrm{E}-4$ $\mathrm{mg} / \mathrm{kg}$; $\mathrm{Cd}$ is $1.11 \mathrm{E}-5 \mathrm{mg} / \mathrm{kg}$; Co is $1.62 \mathrm{E}-4 \mathrm{mg} / \mathrm{kg}$; $\mathrm{Cr}$ is $1.154 \mathrm{E}-5 \mathrm{mg} / \mathrm{kg}$; Ni is $5.97 \mathrm{E}-5$ $\mathrm{mg} / \mathrm{kg}$; $\mathrm{Pb}$ is $2.03 \mathrm{E}-4 \mathrm{mg} / \mathrm{kg} ; \mathrm{Zn}$ is $4.01 \mathrm{E}-4 \mathrm{mg} / \mathrm{kg} ; \mathrm{Fe}$ is $7.08 \mathrm{E}-4 \mathrm{mg} / \mathrm{kg}$. Figure 5 shows that for non-carcinogenic disorders in adults, the total daily heavy metal intake from road dust via eating, cutaneous contact, and inhalation is: As: $1.07 \mathrm{E}-5 \mathrm{mg} / \mathrm{kg} ; \mathrm{Cu}: 2.23 \mathrm{E}-4 \mathrm{mg} / \mathrm{kg}$; $\mathrm{Cd}$ : 1.79E-5 mg/kg; Co: 2.29E-4 mg/kg; Cr: $1.88 \mathrm{E}-5 \mathrm{mg} / \mathrm{kg} ; \mathrm{Ni}: 7.37 \mathrm{E}-5 \mathrm{mg} / \mathrm{kg} ; \mathrm{Pb}: 1.91 \mathrm{E}-4$ $\mathrm{mg} / \mathrm{kg}$; Zn: 4.29E-4 mg/kg; Fe: 6.82E-4 mg/kg; Ni: 7.37E-5 mg/kg; Pb: $1.91 \mathrm{E}-4 \mathrm{mg} / \mathrm{kg}$

\section{Non-Carcinogenic Health Risks: Hazard Quotients (HQ) and Hazard Index (HI)}

Figure 6 shows the hazard quotient (HQ) and hazard index (HI) for non-carcinogenic disorders caused by heavy metals in soils and road dusts in children and adults. For noncarcinogenic disorders in children, the total HQ and HI for heavy metals in soil via ingestion, cutaneous contact, and inhalation are: $\mathrm{Cr}: 8.28 \mathrm{E}-2$; Ni: 6.93E-2; Pb:1.21E+1; Zn: $3.13 \mathrm{E}-2$; As: 7.25E-1; Cu: 1.11E-1; Cd: 4.90E-1; Co: $1.32 \mathrm{E}+1 \mathrm{mg} / \mathrm{kg} ; \mathrm{Cr}: 8.28 \mathrm{E}-2 ; \mathrm{Ni}: 6.93 \mathrm{E}-2$; $\mathrm{Pb}: 1.21 \mathrm{E}+1$; $\mathrm{Zn}: 3.13 \mathrm{E}-2$. the total $\mathrm{HI}$ is $1.60 \mathrm{E}+1$

For non-carcinogenic illnesses in adults, the total HQ and HI for heavy metals in soil via eating, cutaneous contact, and inhalation are shown in Figure 6. The HQ are: Cr: 8.88E-3; Ni: 7.11E-3; Pb: 1.30E-1; Zn: 3.19E-3 mg/kg; As: 7.67E-2; Cu: 1.17E-2; Cd: 5.19E-2; Co: 
5.62E-1 mg/kg; Cr: 8.88E-3; Ni: 7.11E-3; Pb: 1.30E-1; Zn: 3.19E-3 9.45E-5 is the total HI. Table 4 shows that for non-carcinogenic disorders in adults, the total HQ and HI for heavy metals in road dust via eating, cutaneous contact, and inhalation are: $\mathrm{Cu}: 1.34 \mathrm{E}-1$; $\mathrm{Cd}$ : $8.36 \mathrm{E}-$ 2; Co: 7.94E-1; Cr: 1.45E-2; Ni: 8.76E-3; Pb: 1.23E-1; Zn: 3.42E-3. As: 8.31E-2; Cu: 1.34E1; Cd: 8.36E-2; Co: 7.94E-1; Cr: 1.45E-2; Ni: 8.76E-3; Pb: 1.23E-1; Zn: 3.42E-3. The total $\mathrm{HI}$ is $1.12 \mathrm{E}+0$.

\section{Health Quotients (HQ) and Health Index (HI) For Carcinogenic Health Risks}

The hazard quotient (HQ) and hazard index (HI) for heavy metals in soils and road dusts in children and adults for carcinogenic diseases are presented in Figure 6. Figure 6 showed that the total HQ and HI for heavy metals in soil via ingestion, dermal contact and inhalation for carcinogenic diseases in children are: As: 2.80E-5; Cd: 4.99E-10; Co: 1.13E-9; $\mathrm{Cr}: 2.80 \mathrm{E}-5$; Pb: 3.19E-6. The total HI is 4.19E-05. Table 4. showed that the total HQ and HI for heavy metals in road dust via ingestion, dermal contact and inhalation for carcinogenic diseases in children are: As: 3.03E-5; Cd: 8.03E-10; Co: 1.59E-09; Cr: 1.74E-05; Pb: 3.01E06. The total HI is 5.07E-05.

Figure 6 showed that the total HQ and HI for heavy metals in soil via ingestion, dermal contact and inhalation for carcinogenic diseases in children are: As: 1.48E-05; Cd: 1.06E-09; Co: 2.43E-09; Cr: 5.71E-06; Pb: 1.71E-06. The total HI is 2.22E-05. The total HQ and HI for heavy metals in road dust via ingestion, dermal contact and inhalation for carcinogenic diseases in children are: As: 1.60E-05; Cd: 1.72E-09; Co: 3.42E-09; Cr: 9.33E06; $\mathrm{Pb}: 1.61 \mathrm{E}-06$. The total $\mathrm{HI}$ is $2.69 \mathrm{E}-05$.

\section{Statistical Evaluation of Potentially Toxic Metals in Soils and Dusts}

Statisitcal evaluation used in this study were bivariate correlation (BC), hierarchical cluster analysis (HCA) and principal component analysis (PCA). Bivariate correlation of heavy metals in sois showed that there is a strong and positive relationships between As and 
$\mathrm{Cu}(\mathrm{r}=0.614), \mathrm{Cd}(\mathrm{r}=0.684), \mathrm{Cr}(\mathrm{r}=0.940), \mathrm{Pb}(\mathrm{r}=0.751), \mathrm{Zn}(\mathrm{r}=0.705)$ and $\mathrm{Fe}(\mathrm{r}=0.641)$

403

404

405

406

407

408

409

410

411

412

413

414

415

416

417

418

419

420

421

422

423

424

425

(Table 5a). Also there is a strong and positive relationships bewteen $\mathrm{Cu}$ and $\mathrm{Cd}(\mathrm{r}=0.613)$ and $\mathrm{Cr}(\mathrm{r}=0.747)$. There is a strong and positive correaltions between $\mathrm{Cd}$ and $\mathrm{Co}(\mathrm{r}=0.587)$, $\mathrm{Cr}(\mathrm{r}=0.742), \mathrm{Ni}(\mathrm{r}=0.650), \mathrm{Zn}(\mathrm{r}=0.575)$ and $\mathrm{Fe}(\mathrm{r}=0.733)$. Strong and positive realtionships exist between $\mathrm{Cr}$ and $\mathrm{Ni}(\mathrm{r}=0.797), \mathrm{Pb}(\mathrm{r}=0.560), \mathrm{Zn}(\mathrm{r}=0.580)$ and $\mathrm{Fe}(\mathrm{r}=$ 0.510). Nickel has a strong and positive relationships with $\mathrm{Cd}(\mathrm{r}=0.650), \mathrm{Co}(\mathrm{r}=0.580), \mathrm{Cr}$ $(\mathrm{r}=0.797)$ and $\mathrm{Fe}(\mathrm{r}=0.863)$. Also there is a strong and positive realtionships between $\mathrm{Pb}$ and $\mathrm{Zn}(\mathrm{r}=0.856)$ and $\mathrm{Fe}(\mathrm{r}=0.785)$. For road dusts, there is a strong and positive relationships between As and $\mathrm{Cu}(\mathrm{r}=0.788), \mathrm{Co}(\mathrm{r}=0.734), \mathrm{Cr}(\mathrm{r}=0.582), \mathrm{Ni}(\mathrm{r}=0.801)$ and $\mathrm{Zn}(\mathrm{r}=0.552)$ (Table 5b). Also there is a positive and strong correlation between $\mathrm{Cu}$ and $\mathrm{Cd}(\mathrm{r}=0.728), \mathrm{Cr}$ $(\mathrm{r}=0.542), \mathrm{Ni}(\mathrm{r}=0.582), \mathrm{Zn}(\mathrm{r}=0.706)$ and $\mathrm{Fe}(\mathrm{r}=0.797)$. There is a strong and positive correlation between $\mathrm{Cd}$ and $\mathrm{Cr}(\mathrm{r}=0.929), \mathrm{Ni}(\mathrm{r}=0.624), \mathrm{Zn}(\mathrm{r}=0.518)$ and $\mathrm{Fe}(\mathrm{r}=0.580)$. Also, there is a strong and positive relationships between $\mathrm{Co}$ and $\mathrm{Ni}(\mathrm{r}=0.664)$ and $\mathrm{Fe}(\mathrm{r}=$ 0.690). Chromium has a strong and positive relationship with $\mathrm{Pb}(\mathrm{r}=0.640)$ and $\mathrm{Zn}(\mathrm{r}=$ 0.836). Furthermore, strong and positive relationships exist between $\mathrm{Ni}$ and $\mathrm{Zn}(\mathrm{r}=0.573)$ and $\mathrm{Fe}(\mathrm{r}=0.586)$. Strong and positive relationships exist between $\mathrm{Fe}$ and $\mathrm{Pb}(\mathrm{r}=0.553)$ and $\mathrm{Zn}$ $(\mathrm{r}=0.759)$.

For soils, FA classified the heavy metals into five groups (Supplementary 4). For factor 1 , the total is 2.200 with a percentage variance of $24.450 \%$. For factors $2,3,4$ and 5 the total are $1.970,1.531,1.428$ and 1.068 with percentage variances of $21.893 \%, 17.013 \%$, $15.866 \%$ and $11.870 \%$ respectively. For road dusts, FA grouped the heavy metals into four classes (Supplementary 5). For factors 1, 2, 3 and 4 the total are 2.217, 1.776, 1.388 and 1.097 with percentage variances of $24.633 \%, 19.737 \%, 15.423 \%$ and $12.188 \%$ respectively. 


\section{Discussions}

The concentrations of As and $\mathrm{Cr}$ in the area's soils and road dusts were found to be higher than the USEPA (2002) standard and the background sample (Table 1). The concentration of $\mathrm{Cr}$ in road dusts was less than the legal limit. $\mathrm{Cr}$ concentrations in soils and road dusts, on the other hand, were higher than in the control sample. $\mathrm{Cu}, \mathrm{Ni}, \mathrm{Pb}, \mathrm{Zn}$, and $\mathrm{Fe}$ values in the background samples were higher than those in the USEPA (2002) standard. The concentration of heavy metals in the samples are significant $(\mathrm{p}<0.01)$, signifying that anthropogenic activities might have contributed to their availability in the media. Spatial distribution map showed that As in road dusts are more abundant in northeastern to southwestern parts of the study area (Figure 3). Also the concnentration of Cd in road dusts is more available in the central and eastern part of the study area. Ni is more concentrated dusts collected from eastern and southwestern part of the area Chromium is more present in road dusts around the western and central parts of the study area. Cobalt in road dusts of the area are more pronounced in samples from the northwestern and eastern parts of the study area. Lead and $\mathrm{Zn}$ in road dusts of this area are more concentrated in the central and southern parts of the study area. Copper and Fe in the road dusts are more available in the northwestern, central and southwestern part of the study area. Arsenic in road dusts of the study area is lesser than those reported in Moscow, Russia (Vlasov et al. 2019) and Buenos Aires, Argentina (Fujiwara et al. 2011) (Table 2). Also, $\mathrm{Cu}$ in road dusts of Akure is lesser when compared with those in dusts of Moscow, Russia (Vlasov et al. 2020), Beijing, China (Wei et al., 2015) and Buenos Aires, Argentina (Fujiwara et al. 2011). Likewise, Cd in the study area is higher that those found in road dusts of Moscow (Vlasov et al. 2020) and Beijing (Wei et al., 2015) while it is lesser than those reported in dusts of Buenos Aires (Fujiwara et al. 2011). Cobalt in road dusts of Akure area is higher than those of Moscow (Vlasov et al. 2020). The concentration of $\mathrm{Cr}$ in dusts of this area is lesser compared to those obtained in 
Moscow (Vlasov et al. 2020) and Beijing (Wei et al. 2015). The amount of Ni and Zn in road dusts of this area is lesser than those reported in Moscow (Vlasov et al. 2020), Beijing (Wei et al. 2015) and Buenos Aires (Fujiwara et al. 2011). Pb concentrations in dusts from this region are also lower than those reported in road dusts from Moscow (Vlasov et al. 2020), Beijing (Wei et al. 2015), Buenos Aires (Fujiwara et al. 2011), and Lagos (Fujiwara et al. 2011). (Olatunji and Afolabi, 2020).

The concentrations of $\mathrm{As}, \mathrm{Cd}$, and $\mathrm{Cr}$ in this area's soils were higher than the USEPA's (2002) level, but $\mathrm{Cu}, \mathrm{Ni}, \mathrm{Pb}$, and $\mathrm{Zn}$ were lower. The metal contents were significantly higher $(\mathrm{p}<0.01)$ than those in the background samples (Table 1$)$. Arsenic and $\mathrm{Cd}$, in soils of the area is more concentrated in the northern and southern part of the study area than other sampling points (Figure 4). Also, the concentration of Co is more pronounced in the southeastern part of area (Figure 4). The highest concentration of $\mathrm{Cr}$ in soils is obsereved in the northern, southwestern and southeastern parts of the study area (Figure 4). Copper is more concentrated in central and southeaster parts of the study area. Also, the concentration of $\mathrm{Fe}, \mathrm{Ni}$, is more visible in the central parts of the study area. The amount of $\mathrm{Pb}$ in soils is more concentrated in the central, southern and northeastern parts in this area. Also, the concentration of $\mathrm{Zn}$ in soils is more concentrated in the central, southern and eastern parts in this area. Compared with similar studies in cities across the world, the concentration of As in the study area is lower than those reported in Chongqing city, China (Dong et al., 2018) but higher than those reported in Kinshasha, Congo (Ngweme et al., 2020). The amount of $\mathrm{Cu}$ in soils of this area is higher than those reported in Durgapur (Pobi et al., 2017),Chongqing (Dong et al., 2018) and Kinshasha (Ngweme et al., 2020) but lower than those observed in soils of Mexico city (Ihl et al., 2015). Cadmium in soils of this area is higher than those reported in Durgapur (Pobi et al., 2017), Chongqing (Dong et al., 2018) and Kinshasha (Ngweme et al., 2020). The amount of $\mathrm{Cr}$ in the area's soils is lower than in 
477 Durgapur (Pobi et al., 2017), Chongqing (Dong et al., 2018), and Mexico City (Ihl et al., 478 2015), but greater than in Kinshasa (Ngweme et al., 2020).Similarly, the concentration of Ni in soils of this area is lower than those in Durgapur (Pobi et al., 2017), Chongqing (Dong et al., 2018) and Mexico city (Ihl et al., 2015). Lead in soils of Akure area is lower compared with those in Durgapur (Pobi et al., 2017) and Mexico city (Ihl et al., 2015) but higher than those in Chongqing (Dong et al., 2018) and Kinshasha (Ngweme et al., 2020). The concnetration of $\mathrm{Zn}$ in soils of this area is lower than those in Mexico city (Ihl et al., 2015), Chongqing (Dong et al., 2018) and Kinshasha (Ngweme et al., 2020).

According to the geo-accumulation index proposed by Muller (1969), the soils of Akure are unpolluted to moderately contaminated by $\mathrm{As}, \mathrm{Co}, \mathrm{Cr}, \mathrm{Cu}, \mathrm{Pb}, \mathrm{Zn}$, and $\mathrm{Fe}$, but moderately-heavily polluted by $\mathrm{Cd}$ and $\mathrm{Ni}$. $\mathrm{Co}, \mathrm{Cu}, \mathrm{Pb}$, and $\mathrm{Fe}$ were unpolluted to moderately polluted in road dusts from this location, while As and $\mathrm{Zn}$ were moderately to moderatelyheavily polluted (Table 3 ). They were moderately to heavily contaminated with $\mathrm{Cd}$ and $\mathrm{Cr}$. The enrichment factor is a measurement of how much of a given element is found in the earth's crust (Duzgoren-Aydin et al., 2007; Sezgin et al., 2003). According to EF, As, Cd, Co, and $\mathrm{Ni}$ have high background enrichment in the research area's soils, whereas $\mathrm{Cr}, \mathrm{Cu}, \mathrm{Pb}$, and Zn have modest background enrichment. In road dusts, As and Cd have a background to considerable enrichment, whereas $\mathrm{Cu}, \mathrm{Ni}, \mathrm{Pb}$, and $\mathrm{Zn}$ have a background to moderate enrichment. Background enrichment of cobalt was found in dusts, whereas moderate to considerable enrichment of $\mathrm{Cr}$ was seen in the samples. Contamination factor $(\mathrm{CF})$ as porposed by (Hakanson, 1980) and used by Adewumi et al. (2020) unravelled that As, Cu and $\mathrm{Pb}$ poses moderate to very high contamination in the soils, while $\mathrm{Co}, \mathrm{Zn}$ and $\mathrm{Fe}$ showed moderate to considerable contamination of the media (Table 3). Also, Cr showed a low to considerable degree of contamination while $\mathrm{Ni}$ posed a low to very high degree of contamination. The study further revealed that $\mathrm{Cd}$ poses a moderate to very high 
contamination. For road dusts in the area, $\mathrm{Cd}$ and $\mathrm{Cr}$ pose very high contamination while As caused considerable to very high contamination. Also, Co and Ni caused low to considerable contamination while $\mathrm{Cu}, \mathrm{Pb}, \mathrm{Zn}$ and $\mathrm{Fe}$ pose moderate to considerable contamination (Table 3). Heavy metals in the soils of the area, according to Hakanson (1980), pose a moderate to significant level of contamination, but they pose a very high level of contamination in road dusts. Pollution load index (PLI) (Tomilson et al. 1980) further revealed that heavy metals in both soils and road dusts in the city contributes to the pollution of the area (Table 3 ). This further showed that the area is been detoriated by these potentially toxic metals. Enrichment and contamination of soils and dusts above background or geogenic sources are usually due to anthropogenic activities. Continouns expansion of urban centers (Wang et al. 2018; Xie et al. 2019) coupled with rapid industrialization (Proshad et al. 2018), increased waste generation (Wuana and Okieimen, 2011) and intense vehicular movement (Nawrot et al. 2020) might have contributed greatly to high enrichment of metals observed in the soils and road dusts samples. According to Balogun et al. (2011), urban populations in most developing countries have increased by $40 \%$ between 1990 and 1975 . The population of the city in in 1976 was 71,106 and in 2014 it had increased to 476,159 which represents (National Population Commission of Nigeria, 2006). Study by Owoeye and Ibitoye (2016) revealed that there is an increase in built-up areas fro $5.1 \%$ in 1986 to $27.4 \%$ in 2014 . This showed an increase in industrialiazation and definitely a surge in waste production in the area which might have contributed significantly to the release of heavy metals and contamination

522 of the environment. Human and geogenic related activities have inputs too. In this area, human activities that contributed to the concentration of heavy metals in soils include cocoa production industry, petrol station, chemical productions, smelting, mechanic activities, dumpsites, indiscriminate dumping of wastes, incineration, cement depots, markets and quarrying. High and intense vehicular movements, wear and tear of tyres, exhaust fumes from 
527 vehicles and indiscriminate dumping of refuse by road sides contributes greatly to the 528 contamination and pollution of soils and road dusts in this area. Bivariate correlation (Tables 5a and 5b) showed that $\mathrm{As}-\mathrm{Cu}-\mathrm{Cd}-\mathrm{Cr}-\mathrm{Pb}-\mathrm{Zn}$ and $\mathrm{Cd}-\mathrm{Co}-\mathrm{Cr}-\mathrm{Ni}-\mathrm{Zn}-\mathrm{Fe}$ relationships might have originated from smelting activities in the area while $\mathrm{Cr}-\mathrm{Ni}-\mathrm{Pb}-\mathrm{Zn}$ relationships might have been released as a geochemical plume from major landfills and sewage systems in the area. The presence of $\mathrm{Pb}$ in soils and road dusts of the area may be adduced to smelting and high vehicular exhausts. Hierarchical cluster analysis (Figure 7) of metals in soils showed a $\mathrm{Cd}-\mathrm{Cr}-\mathrm{As}, \mathrm{Ni}-\mathrm{Cu}-\mathrm{Pb}-\mathrm{Co}-\mathrm{Zn}$ relationships which reflect smelting, waste generation and disposal and car exhaust as possible sources of metals in the media. HCA (Figure 7) also showed that in road dusts, the associations $\mathrm{Cd}-\mathrm{Cr}-\mathrm{As}-\mathrm{Ni}$ and $\mathrm{Cu}-\mathrm{Pb}-\mathrm{Co}$ reflect air emission of aerosols from smelting, waste disposal, cement storage systems and car exhaust as possible sources. PCA (Figure 8) showed that $\mathrm{Cu}-\mathrm{Ni}-\mathrm{Cr}-\mathrm{Co}-\mathrm{As}-\mathrm{Cd}-\mathrm{Fe}$ association in soils might have been from smelting, burning of fuels, waste disposal, cement dusts, effluents from chemical plants while $\mathrm{Pb}-\mathrm{Zn}$ relationships reflect possible sources as smelting and vehicular exhausts.

Risk assessment is the overall process of identifying the nature of hazards and their level of risk in the environment (CCOHS 2019) which can be inferred from theoretical analysis. The effects of prolonged exposure of various plants and animals to toxic metals have been reported by Fayiga et al. (2007), Chibuike and Obiora (2014), Emamverdian et al. (2015), Sobelev and Begonia (2008), and Eisler (2004). This study uncovered that $\mathrm{Cu}, \mathrm{Zn}$,

$546 \mathrm{Cr}, \mathrm{Ni}$ and $\mathrm{Pb}$ in soils of the area pose slight ecological risks (Table) while $\mathrm{Cd}$ poses medium 547 to higher ecological risks. The total process of identifying the nature of hazards and their level of risk in the environment (CCOHS 2019) that may be derived from theoretical analysis is known as risk assessment. Fayiga et al. (2007), Chibuike and Obiora (2014), Emamverdian et al. (2015), Sobelev and Begonia (2008), and Eisler (2008) have all reported on the impacts of chronic exposure of diverse plants and animals to harmful metals (2004). $\mathrm{Cu}, \mathrm{Zn}, \mathrm{Cr}, \mathrm{Ni}$, 
and $\mathrm{Pb}$ in the soils of the area are shown to represent minor ecological concerns (Table), whereas $\mathrm{Cd}$ poses medium to high ecological risks. Metals in soils posed slight to higher ecological concerns, which were exacerbated by the presence of $\mathrm{Cd}$, according to the overall potential ecological risk index (PERI). $\mathrm{Zn}, \mathrm{Cr}, \mathrm{Ni}$, and $\mathrm{Pb}$ present minor ecological concerns in the area's road dust, but $\mathrm{Cu}$ and $\mathrm{Cd}$ present minor-medium, and minor-high ecological problems. Heavy metals in dusts produced medium ecological concerns, according to PERI, which was prompted by $\mathrm{Cu}$ and $\mathrm{Cd}$. $\mathrm{Cd}$ is toxic to plants, animals, and microorganisms in the ecosystem (UNEP, 2010). Copper is a toxic metal that bioaccumulate in plants and animals (Lenntech, 2021a). Plant diversity decreases in the presence of $\mathrm{Cu}$. Furthermore, the metal can intterupt microbial activities in soils and tends to decrease their organic matter content (Lenntech, 2021a).

The importance of assessing the health risks of heavy metals in soils and dusts in the environment is critical since these toxic metals worsen a variety of human health issues that can lead to death (Laniyan and Adewumi, 2020b). Several research, like Wang et al. (2012) and Adewumi et al. (2020), have found that heavy metals play a substantial role in human health deterioration. The average daily intake (ADI) of $\mathrm{Ni}$ for non-carcinogenic health concerns in soils and road dusts for children and soils for adults was found to be higher than the EFSA-recommended tolerable daily intake limit (2015) (Figure 5). ADI for Pb in soils and dusts for both adults and children were above the daily intake limit suggested by WHO/FAO (2010) while the ADI for Co in road dusts for children were above the limit set by WHO/FAO (2010). For carcinogenic health risks, ADI for Pb in soils and dusts for both adults and children were above the daily intake limit suggested by WHO/FAO (2010). The study showed that children bioaccumulate more heavy metals than adults from both soils and road dusts (Figure 5). In this study, it was observed that health quotients (HQ) for Co and $\mathrm{Pb}$ for both soils and road dusts were above $>1$ for children as suggested by USEPA (2008) 
577 (Figure 6). The hazard index (HI) for non-carcinogenic health concerns from dusts was larger 578 than 1 for both children and adults, whereas the HI for heavy metals in soils was greater than 1 for both children and adults (Figure 6). Non-carcinogenic health concerns are more 580 prevalent in children than in adults. Wang et al. (2012) and Adewumi et al. (2020) both 581 confirmed this (2020). Oral consumption of heavy metals in soils and dusts may exacerbate non-carcinogenic health concerns in the research area. For carcinogenic health risks, HI was lesser than the recommended 1E-4 which implied that both adults and children were at the time of study not prone to carcinogenic health risks. According to Lennetech (2021b), high laden of Co in soils and dusts can lead to asthma, pneumonia, vomiting, nausea, vision problems, heart issues and thyriod damage. It could also instigate cough, shorthness of breath, dyspnea, decreased pulmonary funtion, fibrosis, permanent disability and death. It may also result in weight loss, dermatitis and respiratory hypersensitivity. In Nigeria, approximately 13 million people are diagnosed with clinical asthma (Ozoh et al., 2019). UNICEF (2019) revealed that Nigeria children (under five) make up the highest number of those who died of pneumonia in 2018. Pneumonia accounted for 162,000 death in children which is equivalent to 443 deaths per day/18 hours (UNICEF 2019). Gabriel-Job and Azubogu (2019) pointed out that pneumonia contributed to $19 \%$ of children's death in million Nigerian adults aged 40 years are are blind while 2.7 million of these people have moderate visual impairment. The center also revealed that 400,000 Nigerian adults are 597 severly imparied. Overall, 4.25 million of Nigerian adults in this age bracket are visually impaired. WHO (2018) further showed that $5.60 \%$ of death in the country are caused by coronary heart diseases in Nigeria. Okafor et al. (2019) uncovered that thyriod disorders (TDs) contribute to the total deaths in Nigeria. 
$\mathrm{Pb}$ by pregnant women can cause miscarriages and subtle abortions (Amadi et al. 2017).

603

604

605

606

607

608

609

610

611

612

613

614

615

616

617

618

619

620

621

622

623

624

625

Study in Nigeria revealed that prenatal burden exposure to $\mathrm{Pb}$ through maternal blood and cord was higher than $10 \mathrm{ug} / \mathrm{dl}$ (Obi et al. 2014) and this has been linked to miscarriages in many parts of the country (Amadi et al. 2017). High $\mathrm{Pb}$ in the environment can also lead to high blood pressure. Recent study by Okubadejo et al. (2019) uncovered that adult population in Lagos, Nigeria are classified to have hypertension by the recent guideline. Too much $\mathrm{Pb}$ in the blood stream can further lead to biosynthesis of haemoglobin and anaemia. $\mathrm{Pb}$ toxicity can also lead to chronic kidney damage (Chukwuonye et al., 2018). Chukwuonye et al. (2018) showed that the prevalence of chronic kidney disease (CKD) was high but variable in Nigeria. The presesnce of $\mathrm{Pb}$ in the envioronment can also lead to disruption of nervous system (Komolafe et al. 2018). In Nigeria, Komolafe et al. (2018) revealed that epilepsy and stroke are the commonest neurological disorders in the city of Ile-Ife. Lead in soils and road dusts can also cause brain damage (Lennetech, 2021c). It can also affect men's fertility by causing sperm destruction (Uadia and Empkpae, 2015). According to Uadia and Emokpae (2015), between 40 percent to 50 percent of Nigerian men are infertile. Children's learning ability may be harmed and their behavior may be disrupted as a result of high $\mathrm{Pb}$ levels in the environment (Lennetech, 2021c).

\section{Conclusions}

The contamination of the environment, which is exacerbated by increased human activities, is one of the drawbacks of urbanization. The quantities, extents of contamination, sources, and potential ecological and health consequences of heavy metals in Akure city's soils and road dusts were investigated in this study. The study found that heavy metal concentrations in soils and road dusts in this location were higher than expected, indicating contaminated media. Contamination assessments of these harmful metals revealed a range of 
626 contamination levels from very low to very high, as well as significant levels of pollution in

627 the environment, all of which can be linked to increased human activity in the area. The 628 presence of heavy metals, particularly $\mathrm{Cd}$, may represent a harm to the environment, 629 according to an ecological risk assessment. The city's residents are more susceptible to non630 carcinogenic health risks than carcinogenic health risks, according to a risk assessment.

631 Children are also more exposed to non-carcinogenic health concerns than adults, according to 632 the study. To mitigate the effects of the increasing city, it is suggested that proper 633 environmental regulations be enacted. It's also critical to start educating individuals in the 634 community about the negative effects of heavy metals on public health. Further research into 635 the geochemical fractionation of heavy metals in geological and environmental media is 636 needed to gain a better understanding of their mobility in the area.

\section{Acknowledgements}

638 The authors appreciate Mr. Falade Ayodele of the Department of Geological Sciences, 639 Achievers University, Owo, Ondo State, Nigeria for his assistance during the collection of 640 samples.

\section{Declarations}

642 The authors have no conflicts of interest to declare that are relevant to the content of this 643 article

\section{Funding}

645 The authors did not receive support from any organization for the submitted work.

\section{Compliance with Ethical Standards}

647 No potential conflict exist for this study. This research does not involve the use of animal or 648 human participants. 
No data is asscoaited with this study

651

652

653

654

655

656

657

658

659

660

661

662

663

664

665

666

667

668

669

670

671

\section{References}

Adewumi, AJ, Oladoyin, AF, Oyebamiji, A, Falade, AO, Edema, AA, Emumejakpor, IS. 2019. Finite Strain Analysis of Xenoliths and Phenocrysts in Akure Granitoids, Ondo State, Southwestern Nigeria. Journal of Geography, Environment and Earth Science International, 1-14.

Adewumi, AJ, Laniyan, TA, Xiao, T, Ning, Z and Liu, Y. 2020. Contamination, sources and risk assessments of metals in media from Anka artisanal gold mining area, Northwest Nigeria. Science of the Total Environment. 718:137235.

Adewumi, AJ, Laniyan, TA, Ikhane, PR. 2020. Distribution, contamination, toxicity, and potential risk assessment of toxic metals in media from Arufu $\mathrm{Pb}-\mathrm{Zn}-\mathrm{F}$ mining area, northeast Nigeria. Toxin Reviews. 1-22. 10.1080/15569543.2020.1815787

Amadi, CN, Igweze, ZN, Orisakwe, OE. 2017. Heavy metals in miscarriages and stillbirths in developing nations. Middle East Fertility Society Journal. 22(2):91-100. DOI: $\underline{10.1016 / \text { j.mefs.2017.03.003 }}$

Balogun, IA, Adeyewa, DZ, Balogun, AA, Morakinyo, TE. 2011. Analysis of urban expansion and land use changes in Akure, Nigeria, using remote sensing and geographic information system (GIS) techniques. Journal of Geography and Regional Planning. 4(9): 533-541.

$\begin{array}{llll}\text { CCOHS. } & 2019 . & \text { Risk } & \text { Assessment. }\end{array}$ https://www.ccohs.ca/oshanswers/hsprograms/risk_assessment.html on the 22nd of August 2021 at 15:45 GMT 
672 Chibuike, GU, Obiora, SC. 2014. Heavy Metal Polluted Soils: Effect on Plants and

673

674

675

676

677

678

679

680

681

682

683

684

685

686

687

688

689

690

691

692

693

694

695

Bioremediation Methods. Applied and Environmental Soil Science., 112. https://doi.org/10.1155/2014/752708

Chukwuonye, II et al. 2018. Prevalence of chronic kidney disease in Nigeria: systematic review of population-based studies. International Journal of Nephrology and Renovascular Disease. 11:165-184. doi: 10.2147/IJNRD.S162230

Dong, R, Jia, Z, Li, S. 2018. Risk assessment and sources identification of soil heavy metals in a typical county of Chongqing Municipality, Southwest China. Process Safety and Environmental Protection. 113:275-281.

Duzgoren-Aydin, N.S. (2007). Sources and characteristics of lead pollution in the urban environment of Guangzhou. Science of Total Environment, 385, 182-195.

Duzgoren-Aydin, NS. 2007. Sources and characteristics of lead pollution in the urban environment of Guangzhou. Science of Total Environment. 385:182-195.

EFSA Panel on Contaminants in the Food Chain (CONTAM). 2015. Scientific Opinion on the risks to public health related to the presence of nickel in food and drinking water. EFSA Journal. 13(2), 4002.

Eisler, R. 2004. Arsenic hazards to humans, plants, and animals from gold mining. Reviews of Environmental Contamination and Toxicology, 133-165.

Emamverdian, A, Ding, Y, Mokhberdoran, F. and Xie, F. 2015. Heavy Metal Stress and Some Mechanisms of Plant Defense Response. The Scientific World Journal. 756120:1-18. https://doi.org/10.1155/2015/756120

Fayiga, AO. Ma, LQ, Zhou, Q. 2007. Effects of plant arsenic uptake and heavy metals on arsenic distribution in an arsenic-contaminated soil. Environmental Pollution. 147(3):737-742. 
Fujiwara, F, Rebagliati, RJ, Dawidowski, L, Gómez, D, Polla, G, Pereyra, V, \& Smichowski, P. 2011. Spatial and chemical patterns of size fractionated road dust collected in a megacitiy. Atmospheric Environment. 45(8):1497-1505.

Hakanson, L. 1980. An ecological risk index for aquatic pollution control, a sedimentological approach. Water Resources. 14:975-1001.

ICEH. 2021. Nigeria national blindness and visual impairment survey. A report by International Center for Eye Health (ICEH). Retrieved from https://iceh.lshtm.ac.uk/nigeria-national-blindness-and-visual-impairment-survey/ on August 20, 2021 at 16:45 GMT

Ihl, T, et al. 2015. Concentration of toxic elements in topsoils of the metropolitan area of Mexico City: A spatial analysis using ordinary kriging and indicator kriging. Revista Internacional de Contaminacion Ambiental. 31(1):4762. http://www.scielo.org.mx/scielo.php?script=sci_abstract\&pid=S018849992015000100004\&lng=en\&nrm=iso\&tlng=en

Kasimov, NS, Kosheleva, NE, Vlasov, DV, Nabelkina, KS, Ryzhov, AV. 2019. Physicochemical properties of road dust in Moscow. Geography, Environment, Sustainability, 12(4):96-113.

Komolafe, MA, Owagbemi, OF, Alimi, TI. 2018. The distribution and pattern of neurological disease in a neurology clinic in Ile-Ife, Nigeria. Nigerian Journal of Clinical Practice, 21(11):1520-1524. DOI: 10.4103/njcp.njcp_230_16

Laniyan, TA, Adewumi, AJ. 2020a. Evaluation of contamination and ecological risk of heavy metals associated with cement production in Ewekoro, Southwest Nigeria. Journal of Health and Pollution, 10(25). 
Laniyan, TA, Adewumi, AJ. 2020b. Potential ecological and health risks of toxic metals associated with artisanal mining contamination in Ijero, southwest Nigeria. Journal of Environmental Science and Health, Part A. 55(7):858-877.

Lenntech

(2021a).

Copper-Cu.

Retrieved

from https://www.lenntech.com/periodic/elements/cu.htm on the 22nd of August 2021 at 16:00 GMT

Lenntech

(2021b).

Cobalt-Co.

Retrieved

from https://www.lenntech.com/periodic/elements/co.htm on the 22nd of August 2021 at 16:20 GMT

Lenntech

(2021c)

Lead-Pb.

Retrieved

from https://www.lenntech.com/periodic/elements/pb.htm on the 24th August, 2021 at 16:23 GMT

Li, X., Poon, C.S. \& Liu, P.S. (2001). Heavy metal contamination of urban soils and street dusts in Hong Kong. Applied Geochemistry, 16, 1361-1368.

Muller, G. (1969). Index of geoaccumulation in sediments of the Rhine River. Geojournal. 2:108-118.

National Population Commission (NPC). The 1963, 1991 and 2006 Population Census Reports.

Nawrot, N, Wojciechowska, E, Rezania, S, Walkusz-Miotk, J, Pazdro, K. 2020. The effects of urban vehicle traffic on heavy metal contamination in road sweeping waste and bottom sediments of retention tanks. Science of The Total Environment, 749:141511.

Ngweme, GN, et al. 2020. Heavy metal concentration in irrigation water, soil and dietary risk assessment of Amaranthus viridis grown in peri-urban areas in Kinshasa, 
Obi, E, et al. 2014. Towards prenatal biomonitoring in eastern Nigeria: assessing lead levels and anthropometric parameters of newborns. Journal of UOEH. 36(3), 159-170. DOI: $\underline{10.7888 / \text { juoeh.36.159 }}$

Okafor, EN, et al. 2019. Prevalence and pattern of thyroid disorders among patients attending University of Nigeria Teaching Hospital, Enugu, Southeastern Nigeria. Nigerian Medical Journal: Journal of the Nigeria Medical Association. 60(2):62-77

Okubadejo, NU, et al. 2019). Prevalence of hypertension and blood pressure profile amongst urban-dwelling adults in Nigeria: a comparative analysis based on recent guideline recommendations. Clinical hypertension, 25(1):1-9. https://doi.org/10.1186/s40885$\underline{019-0112-1}$

Olatunji, AS, Afolabi, O.O. 2020. Assessment of Pb contamination of soils, sediments and road dusts of the City of Lagos, Nigeria. Environmental Geochemistry and Health. 42(4):1095-1107.

Owoeye, JO, Ibitoye, OA. 2016. Analysis of Akure Urban Land Use Change Detection from Remote Imagery Perspective. Urban Studies Research. 4673019,:1-9. https://doi.org/10.1155/2016/4673019

Ozoh, O.B. et al. 2019. The prevalence of asthma and allergic rhinitis in Nigeria: a nationwide survey among children, adolescents and adults. PLoS One, 14(9):e0222281. https://doi.org/10.1371/journal.pone.0222281 
Ozoh, O.B. et al. 2019. The prevalence of asthma and allergic rhinitis in Nigeria: a nationwide survey among children, adolescents and adults. PLoS One, 14(9):e0222281. 10.9734/ijtdh/2019/v40i230225

Pobi, KK, Nayek, S, Saha, RN. 2017. Assessment of heavy metals in water, sediment and adjacent soil of a contaminated channel in durgapur industrial zone, West Bengal, India. International Journal of Ecology and Environmental Sciences. 43(4):275-285.

Proshad, R. et al. (2018). Heavy metal toxicity in agricultural soil due to rapid industrialization in Bangladesh: a review. International Journal of Advanced Geosciences. 6(1):83-88.

Sezgin, N, Ozcan, HK, Demir, G, Nemlioglu, S, Bayat, C. 2003. Determination of heavy metal concentrations in street dusts in Istanbul E-5 highway. Environment International. 29:979-985.

Sezgin, N., Ozcan, H.K., Demir, G., Nemlioglu, S. \& Bayat, C. (2003). Determination of heavy metal concentrations in street dusts in Istanbul E-5 highway. Environment International, 29, 979-985.

Sobolev, D, Begonia, M. 2008. Effects of heavy metal contamination upon soil microbes: lead-induced changes in general and denitrifying microbial communities as evidenced by molecular markers. International Journal of Environmental Research and Public Health. 5(5): 450-456.

Tomlinson, DL, Wilson, JG, Harris, CR, Jeffrey, DW. 1980. Problems in the assessment of heavy metal levels in estuaries and the formation of a pollution index. Helgolaender Meeresunter. 33:566-575.

Tomlinson, DL, Wilson, JG, Harris, CR, Jeffrey, DW. 1980. Problems in the assessment of heavy metal levels in estuaries and the formation of a pollution index. Helgolaender Meeresunter. 33:566-575. 
Uadia, PO, Emokpae, AM. 2015. Male infertility in Nigeria: A neglected reproductive health issue requiring attention. Journal of Basic and Clinical Reproductive Sciences. 4(2):45-53. DOI: $\underline{10.4103 / 2278-960 X .161042}$

UNEP (2010) Final review of scientific information on cadmium. 204 pp.

UNICEF (2019) Nigeria contributes highest number to global pneumonia child deaths. Retrieved from https://www.unicef.org/nigeria/press-releases/nigeria-contributeshighest-number-global-pneumonia-child-deaths on August 21st 2021 at 15:45 GMT

USEPA (2002) Supplemental guidance for developing soil screening levels for superfund sites. Office of Solid Waste and Emergency Response, Washington, D.C. Retrieved $\begin{array}{llll}\text { on } & 30^{\text {th }} & \text { the } & \text { August }\end{array}$ athttp://www.epa.gov/superfund/health/conmedia/soil/index.htm.

USEPA. (2002) Supplemental guidance for developing soil screening levels for superfund sites. Office of Solid Waste and Emergency Response, Washington, D.C. Retrieved $\begin{array}{llll}\text { on } & 30^{\text {th }} & \text { August } & 2018\end{array}$ athttp://www.epa.gov/superfund/health/conmedia/soil/index.htm.

Wang, M, Liu, R, Chen, W, Peng, C, Markert, B. 2018 Effects of urbanization on heavy metal accumulation in surface soils, Beijing. Journal of Environmental Sciences, 64:328-334.

Wang, Y, Qiao, M, Liu, Y, Zhu, Y. 2012. Health risk assessment of heavy metals in soils and vegetables from wastewater irrigated area, Beijing-Tianjin city cluster, China. Journal of Environmental Sciences. 24(4), 690-698.

Wei, X, Gao, B, Wang, P, Zhou, H, Lu, J. 2015. Pollution characteristics and health risk assessment of heavy metals in street dusts from different functional areas in Beijing, China. Ecotoxicology and Environmental Safety. 112:186-192. 
813 WHO (2018). Nigeria: Coronary Heart Disease. Retrieved from

https://www.worldlifeexpectancy.com/nigeria-coronary-heartdisease\#: :text=Nigeria\%3A\%20Coronary\%20Heart\%20Disease \&text=According $\% 20$ to $\% 20$ the $\% 20$ latest $\% 20 \mathrm{WHO}$, Nigeria\%20\%2331\%20in\%20the $\% 20$ world on August 23, 2021 at 15:44 GMT

World Health Organization. 2016. Manual on Development and Use of FAO and WHO Specifications for Pesticides. Food \& Agriculture Org. retrieved at http://www.fao.org/3/y4353e/y4353e.pdf on the August 23 at 12:12 GMT

Wuana, AE, Okieimen, F.E. 2011. Heavy Metals in Contaminated Soils: A Review of Sources, Chemistry, Risks and Best Available Strategies for Remediation", International Scholarly Research Notices. 402647:120. https://doi.org/10.5402/2011/402647

Xie, T, Wang, M, Chen, W, Uwizeyimana, H. 2019. Impacts of urbanization and landscape patterns on the accumulation of heavy metals in soils in residential areas in Beijing. Journal of Soils and Sediments.19(1), 148-158. 
Figures

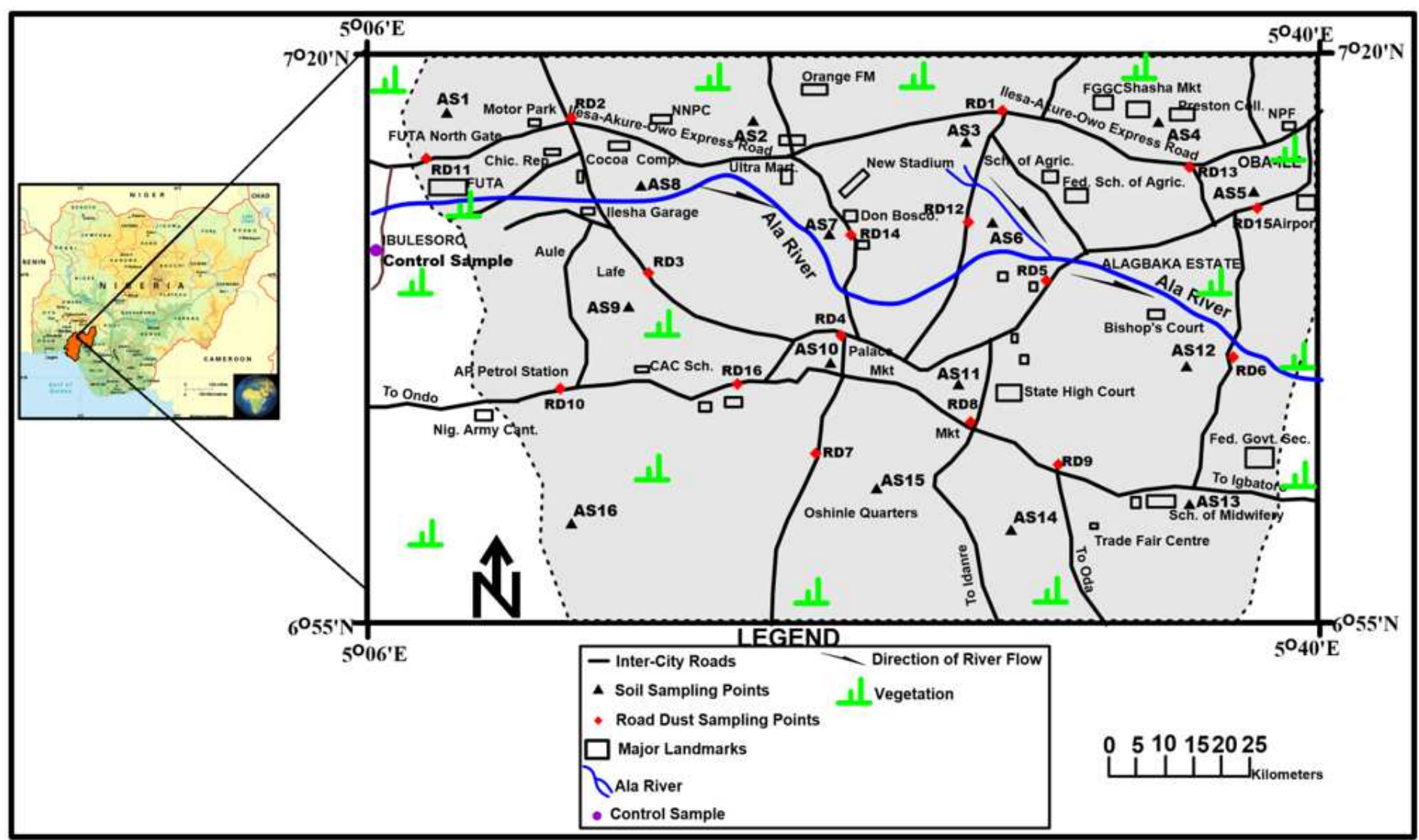

Figure 1

Location map of the study area showing the sampling points 


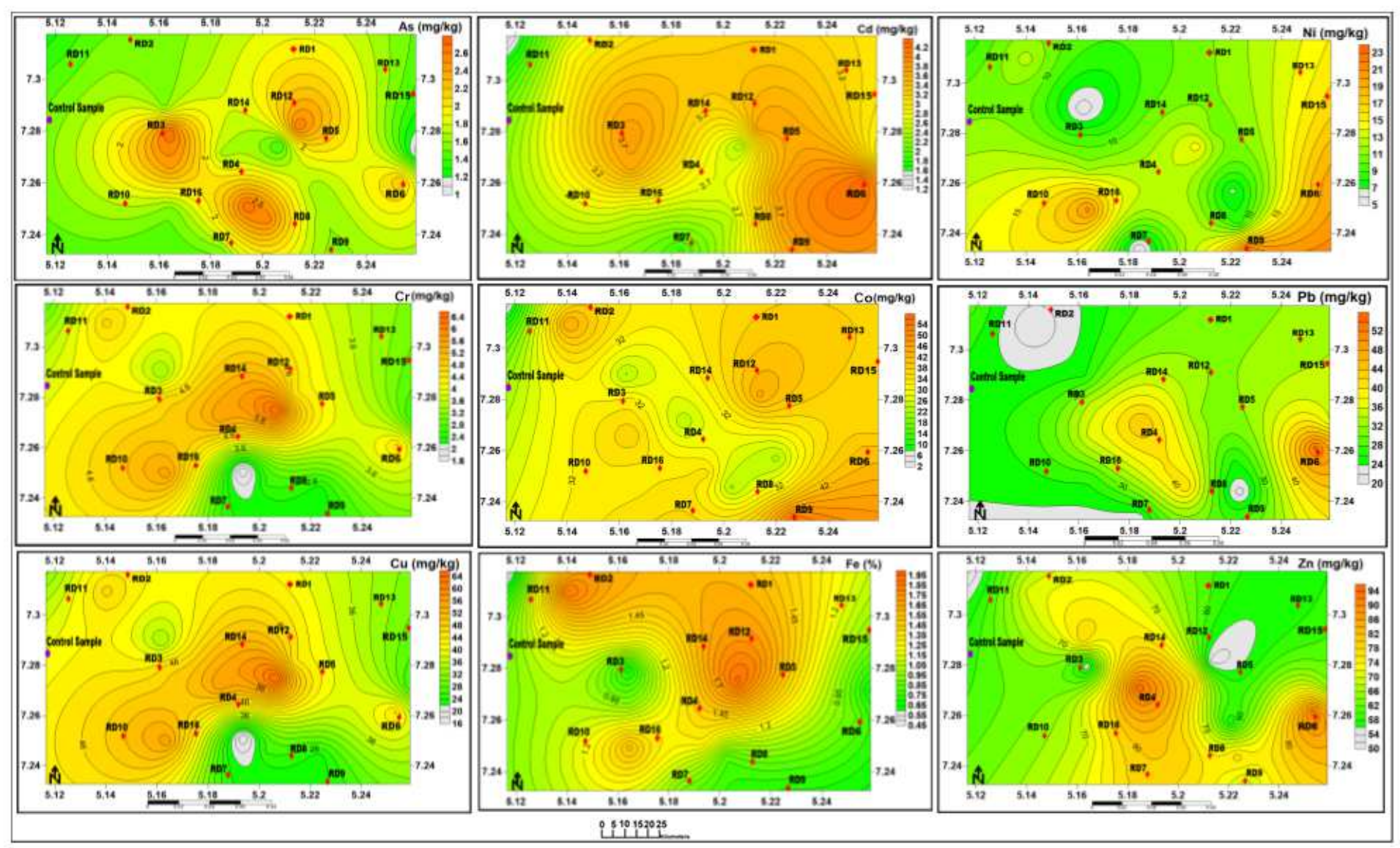

Figure 2

Spatial Distribution of Heavy Metals in Road Dusts 


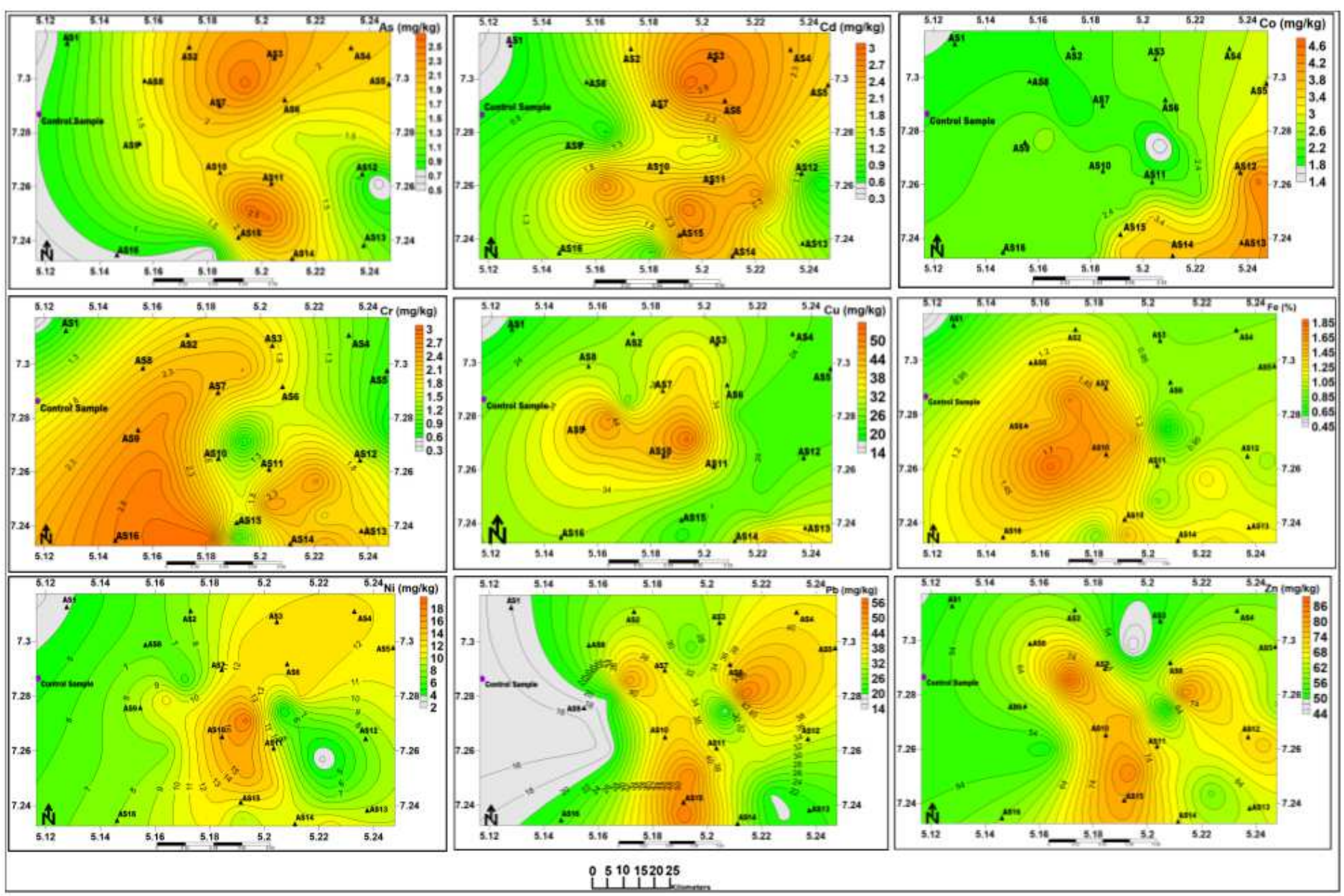

Figure 3

Spatial Distribution of Heavy Metals in Soils 


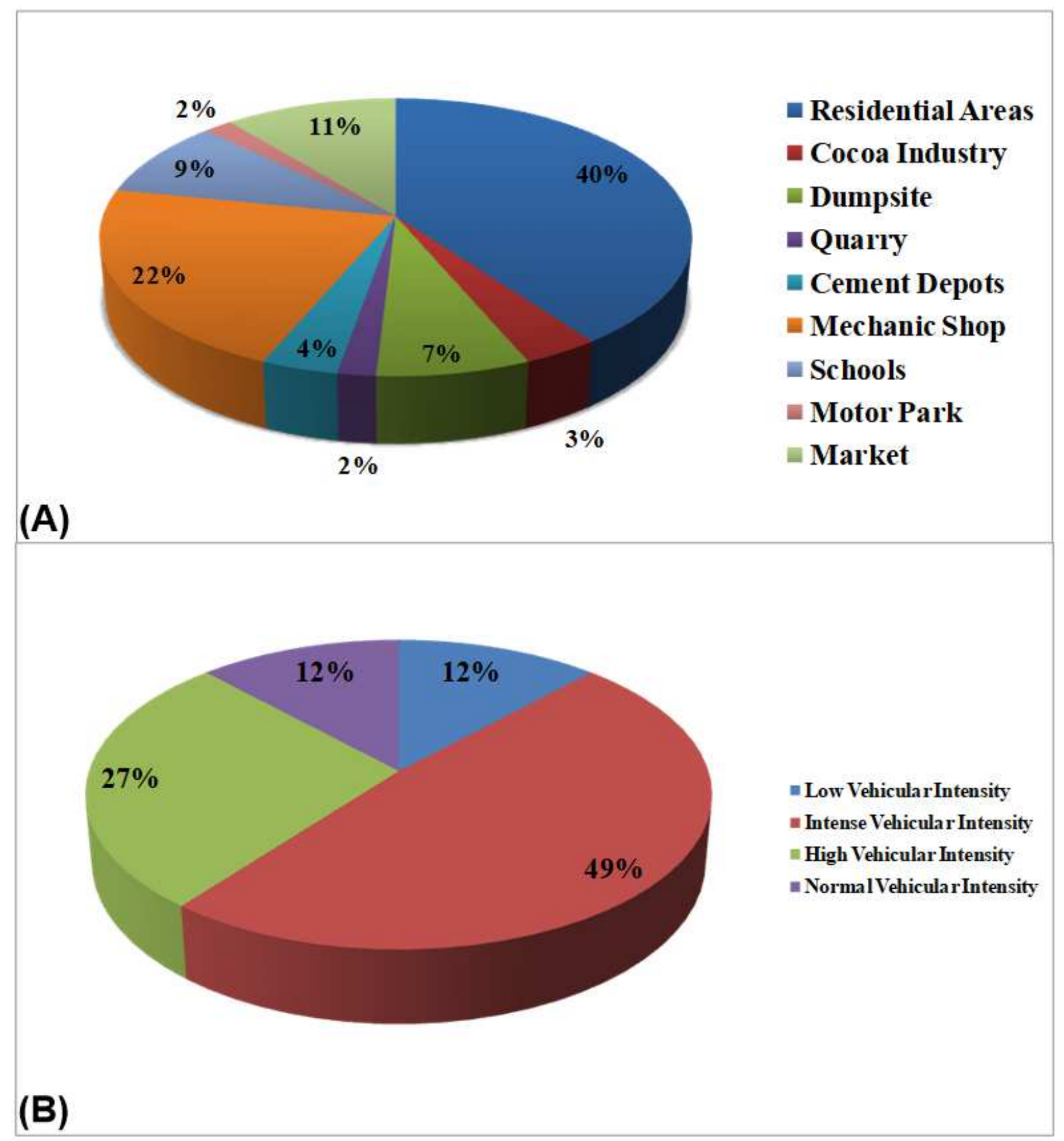

Figure 4

Percentage human activities (A) and vehicular intensity (B) around soils and road dust sampling points 


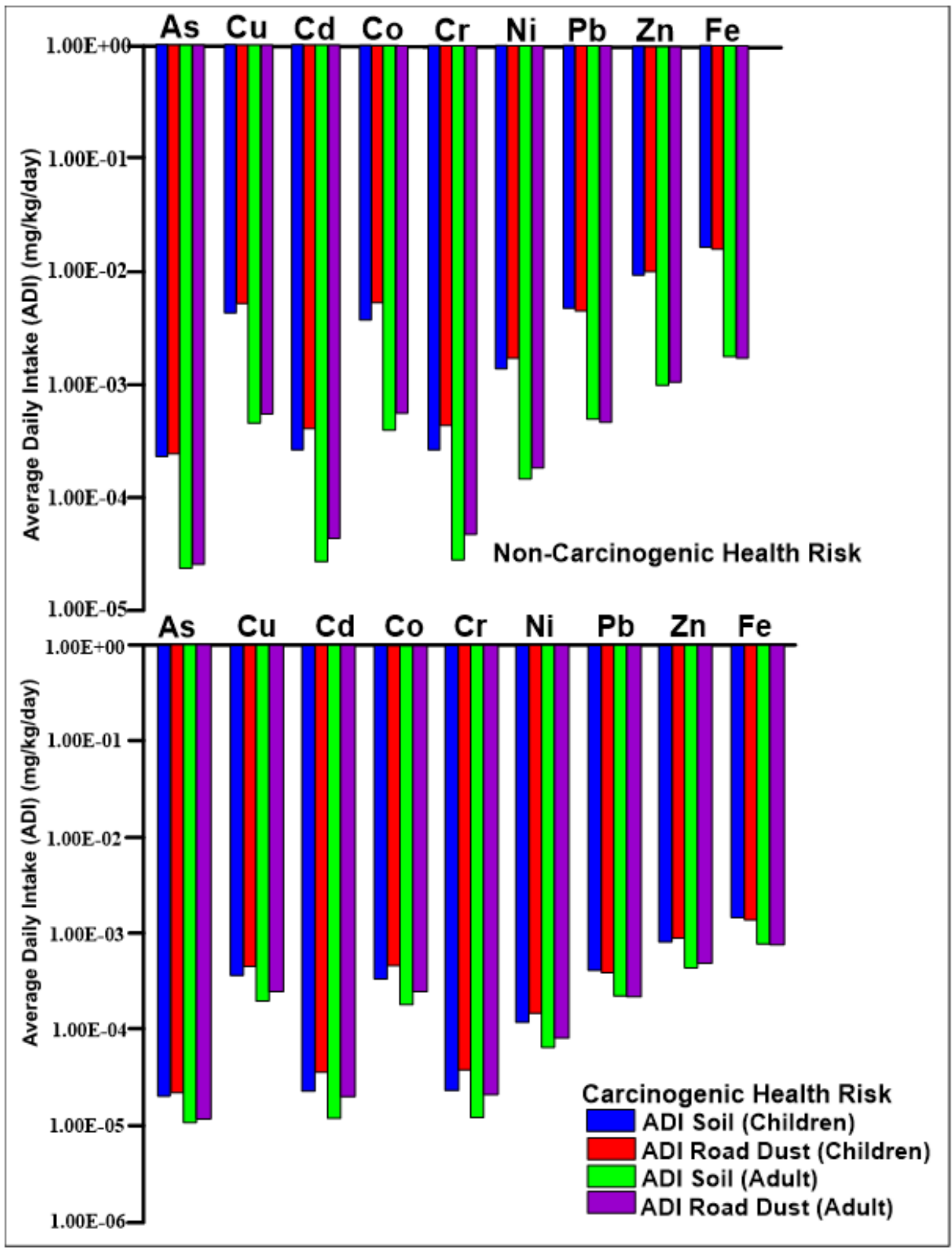

Figure 5

Mean ADIs for non-carcinogenic and carcinogenic health risks of potentially toxic metals in soils and dusts in the study area 


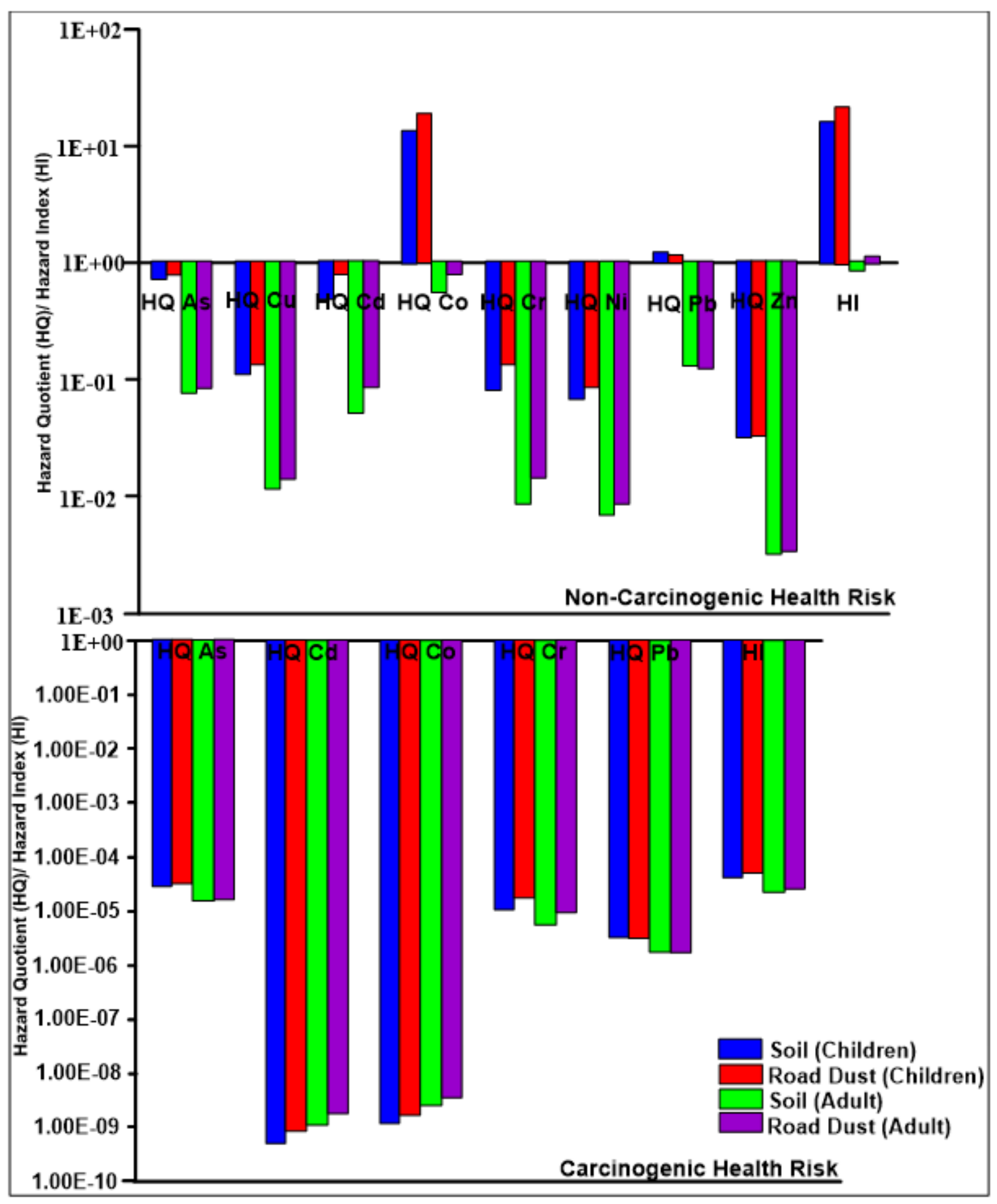

Figure 6

Average hazard quotient $(\mathrm{HQ})$ and hazard index $(\mathrm{HI})$ for non-carcinogenic and carcinogenic health risks of potentially toxic metals in soils and dusts in the study area 

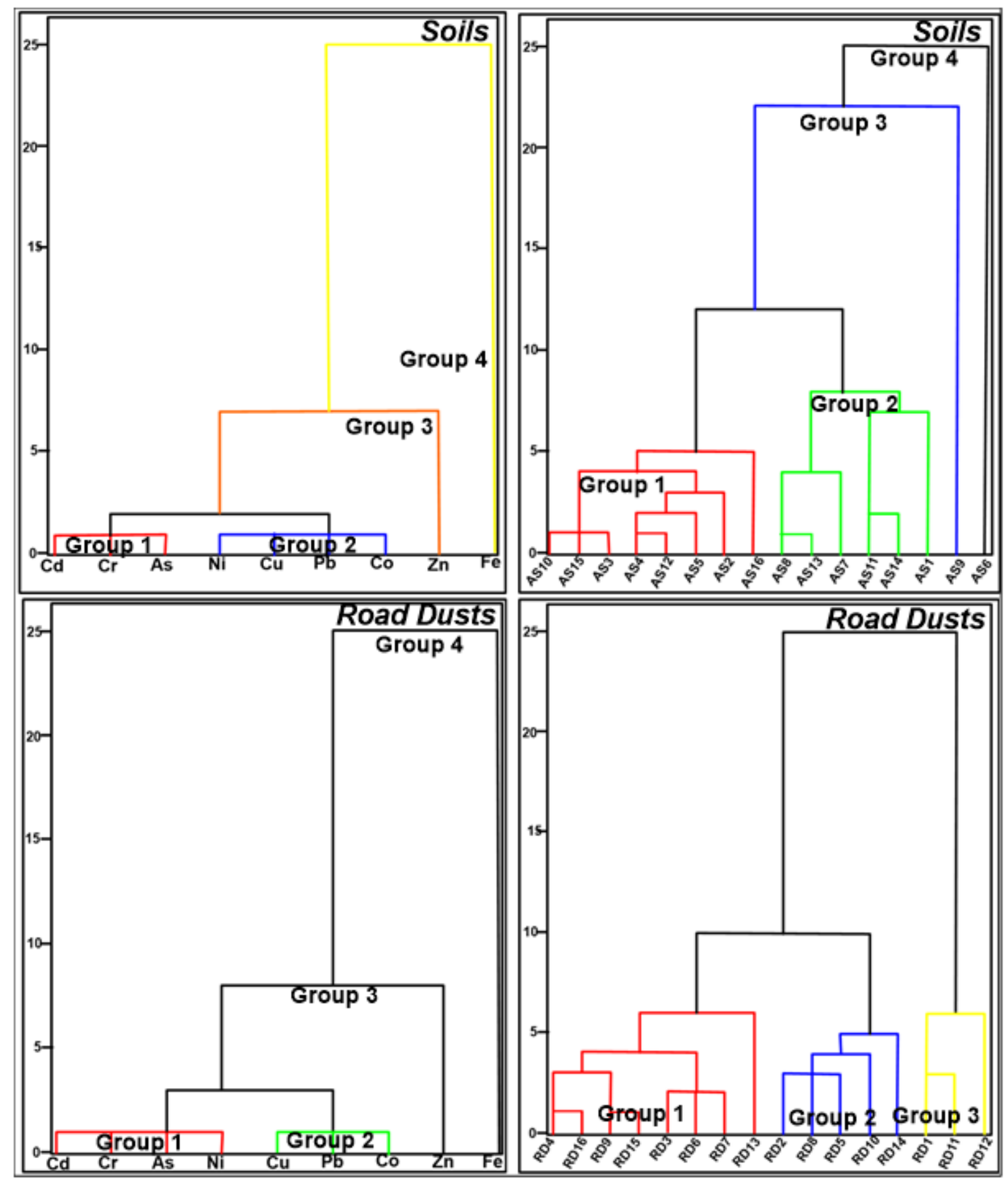

Figure 7

Hierarchical cluster analysis ( $\mathrm{HCA})$ of metals and sampling points 


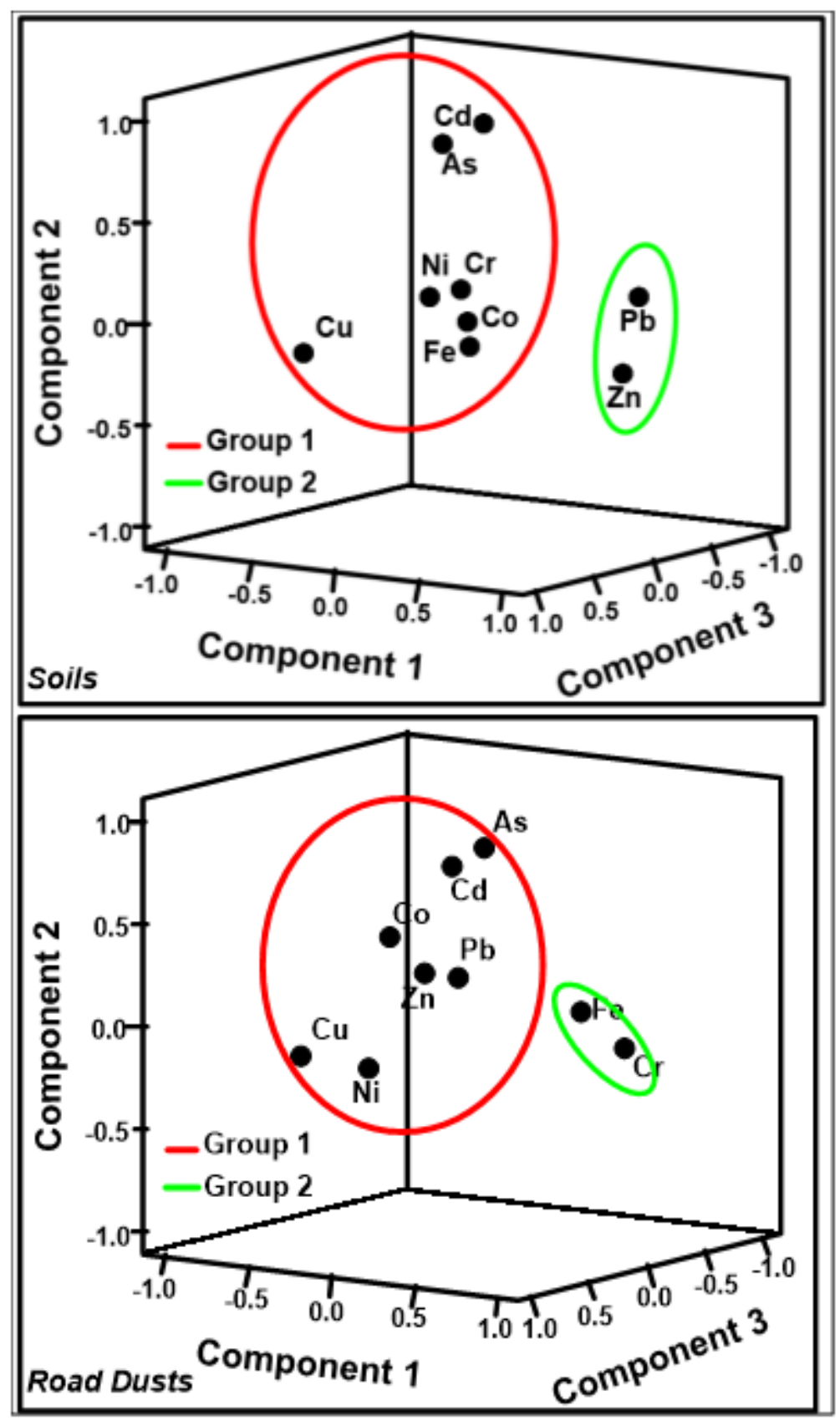

Figure 8

Principal component analysis of heavy metals in soils and road dust

\section{Supplementary Files}

This is a list of supplementary files associated with this preprint. Click to download.

- Supplementarydata.docx 